\title{
Horizontal Grid Size Selection and its Influence on Mesoscale Model Simulations
}

\author{
Rosa SALVADOR \\ CEAM (Centro de Estudios Ambientales del Mediterraneo), Paterna, Valencia, Spain \\ Josep CALbó \\ Departament d'Enginyeria Industrial, Universitat de Girona, Girona, Spain \\ MiLlán M. MiLLÁN \\ CEAM (Centro de Estudios Ambientales del Mediterraneo), Paterna, Valencia, Spain
}

(Manuscript received 17 April 1998, in final form 23 November 1998)

\begin{abstract}
The use of two-dimensional spectral analysis applied to terrain heights in order to determine characteristic terrain spatial scales and its subsequent use for the objective definition of an adequate grid size required to resolve terrain forcing are presented in this paper. In order to illustrate the influence of grid size, atmospheric flow in a complex terrain area of the Spanish east coast is simulated by the Regional Atmospheric Modeling System (RAMS) mesoscale numerical model using different horizontal grid resolutions. In this area, a grid size of $2 \mathrm{~km}$ is required to account for $95 \%$ of terrain variance. Comparison among results of the different simulations shows that, although the main wind behavior does not change dramatically, some small-scale features appear when using a resolution of $2 \mathrm{~km}$ or finer. Horizontal flow pattern differences are significant both in the nighttime, when terrain forcing is more relevant, and in the daytime, when thermal forcing is dominant. Vertical structures also are investigated, and results show that vertical advection is influenced highly by the horizontal grid size during the daytime period. The turbulent kinetic energy and potential temperature vertical cross sections show substantial differences in the structure of the planetary boundary layer for each model configuration.
\end{abstract}

\section{Introduction}

Episodes of increased surface ozone concentration in violation of European Commission (EC) directive 92/ 72/CEE continuously occur on the Spanish east coast (Millán et al. 1997). Wind fields and turbulence patterns simulated by mesoscale models could help in interpreting experimental data and describing the flow dynamics of the photochemical processes involved. Errors in wind prediction by mesoscale models could lead to large errors in pollutant dispersion patterns when these models are coupled to photochemical models. Also, the Valencia region on the Spanish east coast has been affected recently by a significant increase in wildfires (Millán et al. 1998). The ability to use mesoscale models to predict accurate wind fields in a reasonable computational time would help in the management of such critical situations as fires or air pollution episodes. The rapid development of computational resources has made

Corresponding author address: Dr. Rosa Salvador, CEAM, Parque Tecnologico, Calle 4, Sector Oeste, E-46980 Valencia, Paterna, Spain. E-mail: salvador@ceam.es the use of complex models more feasible. However, configuration of such models can be a difficult task and should be done with care.

For those cases in which synoptic-scale forcing is weak, as is the typical case for summertime in Spain, topographical-scale forcing can have an important effect on mesoscale atmospheric flow and therefore on the dispersion and fate of air pollutants. There are other surface features (land use type, soil textures, roughness, soil moisture content, etc.) that play an important role in mesometeorological processes. These surface characteristics should be analyzed in detail. However, if surface topography is a major driving force on the mesoscale atmospheric processes involved, then grid size and the domain of nested grids should be influenced primarily by local topography. Analysis of the terrain inhomogeneities is a necessary (although not sufficient) step in the process of establishing the required horizontal grid size for a mesoscale model application (Pielke 1984). The averaging volume defined by the model's horizontal grid spacing must be sufficiently small to allow the mesoscale forcing and responses to be represented accurately. On the other hand, small-scale topographical features captured by small grid spacing in 
the model can result in numerical instabilities that contaminate predictions. For all these reasons, and since computational requirements increase markedly with the inverse of the grid spacing (for a given domain), the horizontal grid size becomes an important design decision (Lyons et al. 1993). Surprisingly, however, the grid very often is selected without considering any accurate study of its optimum size.

Therefore, modelers frequently ask about the optimum grid size to describe some observed atmospheric phenomenon satisfactorily by means of a mesoscale numerical model. The representation of the topographical surface in wavelength space can be used to determine the spatial scales that are characteristic of a given terrain. This process may be accomplished by a spectral analysis of terrain heights, which can give the horizontal grid resolution needed to resolve adequately the entire range of terrain scales when a mesoscale model is going to be used (Young and Pielke 1983). Obviously, the analysis of terrain variance described here is most suitable for terrain-forced atmospheric phenomena. For determining appropriate grid spacing for atmospheric phenomena that are not intimately connected to the topographic scale, analysis of terrain variance is not appropriate.

Since the terrain is bidimensional, it would be preferable to use a bidimensional Fourier transform. However, in the 1980s these routines were not readily available for handling such a large amount of data, and unidimensional Fourier transforms were used instead. For these cases, the spectrum of the topography was represented in wavelength space along some cross sections where the greatest terrain gradient occurred. Steyn and Ayotte (1985) pointed out, however, that the use of unidimensional terrain spectra to indicate the required grid size to be used with a numerical model can lead to incorrect conclusions if there is a spatial directionality in the topography structure. On the other hand, twodimensional spectral analysis is being used now in different studies where the horizontal spatial pattern is of interest. For example, Rayner (1972) used a 2D Fourier transform to analyze terrain morphology, as we do in this paper; Ford (1976) applied this technique to a forest canopy and Garand (1988) did so for cloud pattern recognition. Porch (1982) studied autospectral analyses of drainage wind fluctuations and suggested that a relationship may exist between prominent spectral peaks and regular variations in complex terrain as represented by a two-dimensional Fourier transform of the terrain heights. Moreover, in the framework of linear wind flow models, Troen and Petersen (1989) showed that the solution for a neutrally stratified flow over topography can be given by a series of Fourier-Bessel functions. Coefficients in this series can be found directly from a series decomposition of the slope of topography in the area of interest. Similar scale dependence of speedup over shallow hills is given by Wamsley et al. (1982) in which the magnitude of mean flow speed over a hill is related to surface roughness and the half-length and height of the hill.

In this paper, the application of two-dimensional spectral analysis to terrain heights and its subsequent use for the objective definition of a grid size that is adequate to resolve terrain forcing are presented. An area of complex terrain on the east coast of the Iberian Peninsula is chosen on which to apply these analyses. Although topography is not the only driving mechanism that contributes to meteorological conditions in this area, it plays a major role and should be well resolved in modeling exercises. In order to illustrate the influence of grid size, several simulations with a mesoscale numerical model are carried out using different grid resolutions. Horizontal wind fields obtained by using these different resolutions are compared through the analysis of streamlines and wind patterns. The vertical structure of the atmospheric flow also is investigated by comparing vertical wind components, vertical distribution of turbulent kinetic energy, and potential temperature vertical patterns. Meteorological data required for simulations and comparisons were taken from the historical dataset obtained during the Mesometeorological Cycles of Air Pollution in the Iberian Peninsula project (MECAPIP), carried out from 1988 to 1991.

\section{Data and methods}

\section{a. Topography data and site}

For this study, the basic domain is an area of $150 \mathrm{~km}$ $\times 150 \mathrm{~km}$ centered approximately in the city of Castellón, on the east coast of the Iberian Peninsula (Fig. 1). Since 1986, several EC-supported experimental campaigns have been carried out in this area in the frame of the following projects: MECAPIP (Millán et al. 1992; 1996), Regional Cycles of Air Pollution in the WestCentral Mediterranean Area (RECAPMA) (Millán et al. 1997), South European Cycles of Air Pollution (SE$\mathrm{CAP}$ ), and the most recent Biogenic Emissions in the Mediterranean Area (BEMA) (Seufert 1997). Other works concerning air pollution also have focused on this area (Martín et al. 1991; Salvador et al. 1994; Hernández et al. 1995). The area is broadly considered to be a representative experimental site of the Western Mediterranean Basin for investigating photochemical processes.

Two different topographical databases were used in this study. The Spanish Geographical Service (SGS) topographical database with $\delta x=200 \mathrm{~m}$ of resolution in the horizontal and $1 \mathrm{~m}$ in the vertical was used as basic data for the spectral analysis. Therefore, the domain is described by an array of $750 \times 750$ values. For model simulations, the United States Geographical Service (USGS) database with $30^{\prime \prime}$ of resolution was used with a domain of $180 \mathrm{~km} \times 145 \mathrm{~km}$ in size; $30^{\prime \prime}$ of latitude correspond to $925 \mathrm{~m}$ and, at a latitude of $40^{\circ} \mathrm{N}$, $30^{\prime \prime}$ of longitude is $710 \mathrm{~m}$. This worldwide database was 

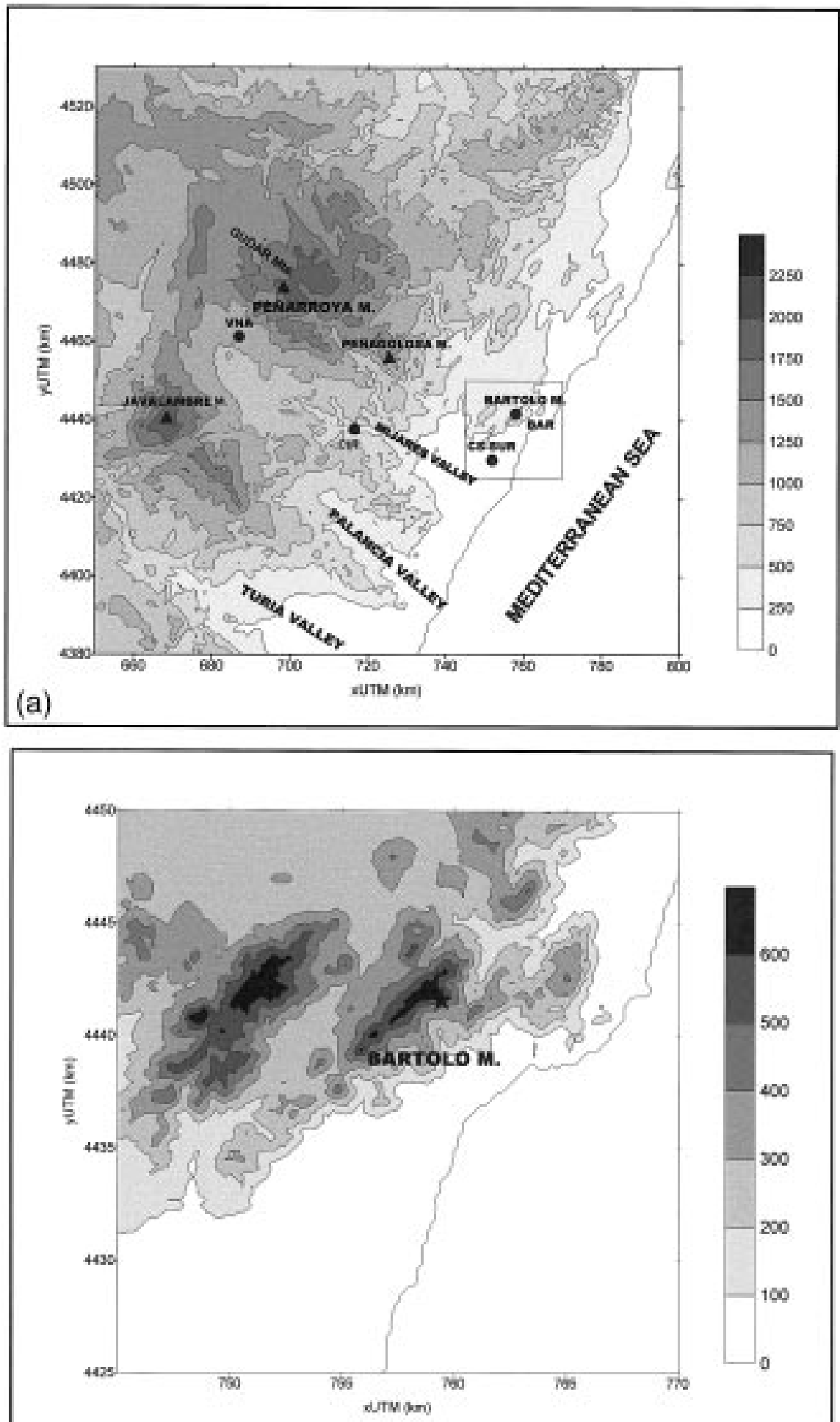

(b)

FIG. 1. (a) Map of the studied domain from the SGS, showing major topographic features and position of ground-based monitoring stations (CS-SUR, CIR, BAR, and VNA; defined in section $3 b$ ). Contour lines are plotted every $250 \mathrm{~m}$. (b) A more detailed topography zoom of the Bartolo Mountain area. The monitoring station BAR is plotted as a star. 
used for modeling purposes because several sensitivity studies of the interactions that occur local up to global scales (not shown in this paper) are being carried out using the nesting capabilities of the model (Millán et al. 1999). Figure 1a represents the topographic map of the domain at the best resolution available from the graphics software package used, that is, only every fifth point from the SGS 200-m resolution data is represented.

The main characteristics of the domain topography are a flat strip along the coast delimited by a mountain range oriented in the northeast-southwest direction. This coastal mountain range is crossed by several valleys along which the sea breeze can penetrate inland; one of them is the narrow Mijares River Valley, where monitoring stations were located and the modeling domain was centered. There are two major mountain peaks, Peñarroya $(2024 \mathrm{~m})$ and Javalambre $(2020 \mathrm{~m})$, at the sides of this valley. A small section of the domain, centered on Bartolo Mountain, is shown in more detail as a basis for further discussions (Fig. 1b). The coastal mountain range orientation (SW-NE), together with arid land cover, favors a rapid solar heating of slopes and an early onset of the sea breeze, aided by the upslope winds. Because of the orientation of the mountain range, the sea breeze is intensified by thermal effects but would be suppressed by mechanical effects, except at some valleys where the flow is channeled. The great influence of topography on the evolution of the sea breeze has been analyzed previously based on experimental data, and the results of this analysis have been reported elsewhere (Millán et al. 1996).

\section{b. Spectral analysis}

As previously stated, the Fourier transform has been the main tool used to define the optimum grid size in the present analysis. Before applying the Fast Fourier Transform (FFT) routine, however, the digitized terrain data underwent several modifications. First, SGS terrain data were fitted to a linear function (i.e., a plane) and this function was subtracted from all terrain heights. With this step, the main tendency of the data, which could have produced a very large amount of spectral energy at wavenumber 0, was removed. Second, a multiplying filter having a value of unity over most of the domain and a cosine shape at the borders was applied in order to reduce the variance introduced by the edge discontinuity (Rayner 1972). Last, since the domain did not have a number of points equal to a power of 2 in any direction, a buffer of 0 values was added around the domain to get the final $1024 \times 1024$ points domain. This zero-padding procedure to augment the domain size is necessary for numerical routine requirements and is convenient since it helps to reduce typical discrete Fourier transform problems such as power filtering.

After this process, a standard 2D FFT routine (Press et al. 1988) was applied over the resulting height values.
The result is the complex amplitudes of the harmonics that correspond to each wavenumber $k$. The module of these complex amplitudes constitutes the spectral energy function. Normalizing this function by the total size of the analyzed domain, we obtained the spectral power function $S$, which was the basis for further analysis. Note that since the initial signal (i.e., topographic heights) is real, the corresponding Fourier transform and, therefore, the spectral power are symmetric functions with respect to the origin. This symmetry means that, although the wavenumbers vary from $-1 /(2 \delta x)$ to $1 /(2 \delta x)$ in both (south-north and west-east) directions, the analysis of one half of this domain gives all the information contained in the function. In this work, positive wavenumbers for the west-east direction and the whole range of wavenumbers for the south-north direction arbitrarily were chosen.

\section{c. Model description and setup}

The Regional Atmospheric Modeling System, Version 3b (RAMS; Pielke et al. 1992) was used in this study. The simulations used the following available options: 3D nonhydrostatic atmosphere in a terrain-influenced vertical coordinate system with polar stereographic horizontal coordinates. The vertical diffusion coefficients were computed with the turbulence closure scheme of Mellor and Yamada (1982), and for horizontal diffusion coefficients the first-order scheme of Smagorinsky was used. For these simulations no cumulus or microphysical parameterizations were included. A rigid top at $14 \mathrm{~km}$ with no absorbing layer was set at the upper boundary. However, top-boundary nudging (which damps gravity waves) for horizontal inhomogeneous initialization was activated and is analogous to the absorbing layer top boundary conditions. At the lower boundary, the surface fluxes of heat, moisture, and momentum were calculated, and the differences in temperature and moisture between air and surface were fully interactively handled by employing a soil model and zero-gradient lateral boundary conditions. A homogeneous loamy sand soil with crop/mixed-farming vegetation was assumed in this study to avoid grid size-based spatial inhomogeneities other than those from topography.

A nonhomogeneous initialization with nonstationary boundary conditions was used. The model was run for 27 July 1989, when both field data from the MECAPIP project and European Centre for Medium-Range Weather Forecasts (ECMWF) global data were available. The latter data, with $1^{\circ}$ resolution of latitude and longitude, were used for initialization since there were no free soundings in the modeled area. The data were ingested into the isentropic analysis package of RAMS as part of the model initialization procedure. The model was run for $30 \mathrm{~h}$, starting at 1800 UTC (same as local time, since the Greenwich meridian crosses the domain) on 26 July 1989, to allow model numerical spinup. Cli- 
TABLE 1. Summary of characteristics distinguishing among the different test runs carried out using the RAMS model. The distances $\Delta x, \Delta y$ are the horizontal grid spacings, $\Delta z_{1}$ is the thickness of the lowest grid layer; $N_{x}, N_{y}, N_{z}$ are the number of grid cells in each direction; CPU is the central processing unit time required by an IBM RS/6000-55L workstation to simulate $1 \mathrm{~h}$.

\begin{tabular}{lcccrc}
\hline \hline Run No. & $\begin{array}{c}\text { Number of } \\
\text { grids }\end{array}$ & $\begin{array}{c}\Delta x, \Delta y \\
(\mathrm{~km})\end{array}$ & $\Delta z_{1}(\mathrm{~m})$ & $N_{x}, N_{y}, N_{z}$ & $\begin{array}{c}\mathrm{CPU} \\
\left(\mathrm{min} \mathrm{h}^{-1}\right)\end{array}$ \\
\hline Test 1 & 1 & 6 & 120 & $30,25,24$ & 7 \\
Test 2 & 1 & 4 & 120 & $45,37,24$ & 16 \\
Test 3 & 1 & 2 & 120 & $90,74,24$ & 72 \\
Test 4 & 1 & 1.5 & 120 & $120,99,24$ & 125 \\
Test 5 & 1 & 2 & 20 & $90,74,34$ & 136 \\
\hline
\end{tabular}

matological values of sea surface temperatures also were used for initialization, and the USGS dataset was used for defining the underlying terrain. Nesting capabilities were not considered in order to avoid influences on the model results other than those caused by horizontal grid spacing. It is well known, however, that it is necessary to include interaction between scales to compose the whole picture of atmospheric circulations in the studied area (Millán et. al. 1992, 1996, 1997). Thus, four dif- ferent model configurations of grid size were tested. The horizontal grid spacing was set to $6,4,2$, and $1.5 \mathrm{~km}$, and a vertical variable-grid stretching with higher resolution near the ground and the lowest layer top at 120 $\mathrm{m}$ above ground level (AGL) was used. An additional test with finer vertical resolution was included in which the lowest layer was set at $20 \mathrm{~m}$ AGL. The five different model configurations are summarized in Table 1. All the simulations were performed on an IBM RS/6000$55 \mathrm{~L}$ workstation.

\section{Results and discussion}

\section{a. Spectral analysis}

Isopleths of $S\left(\mathrm{~m}^{2} \mathrm{~km}^{2}\right)$, are represented in Fig. 2 versus both $x$ and $y$ wavenumbers $\left(\mathrm{km}^{-1}\right)$. This representation is especially useful to detect any directionality in the studied topography (Steyn and Ayotte 1985). In Fig. 2a, the range of wavenumbers was limited from 0 to $1 \mathrm{~km}^{-1}$. Although the data allow us to obtain results for wavenumbers as big as $2.5 \mathrm{~km}^{-1}$ (equivalent wavelength $\lambda=0.4 \mathrm{~km}$ ), the spectral energy for wave-

(a)

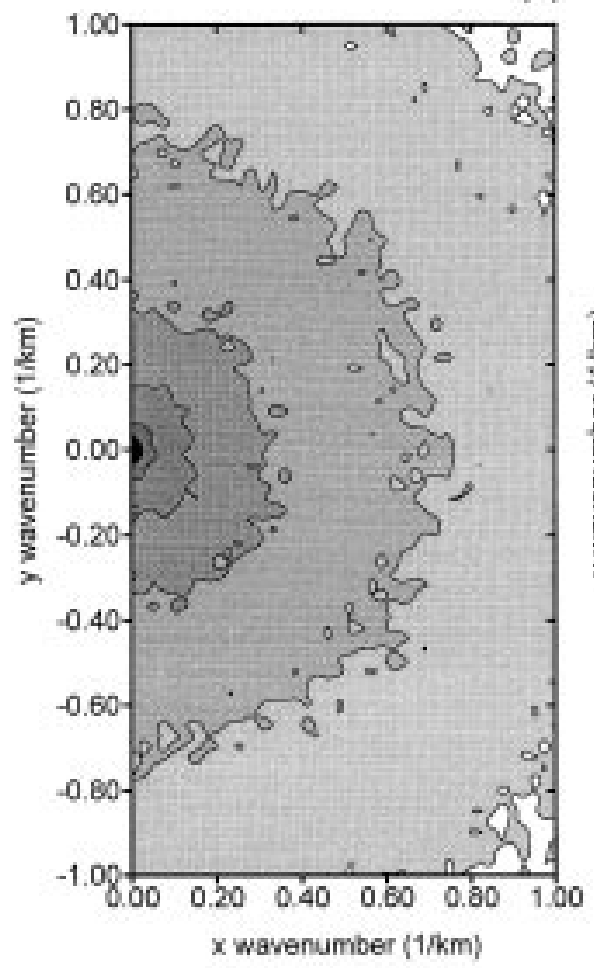

(b)

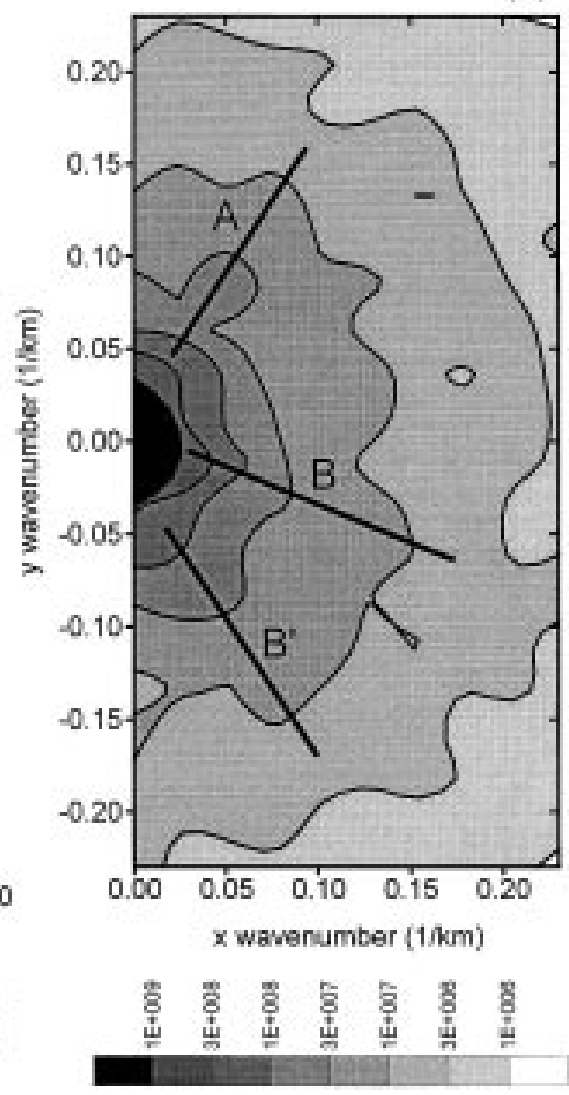

FIG. 2. Isopleths of spectral power $\left(\mathrm{m}^{2} \mathrm{~km}^{2}\right)$ contained in the terrain height, after applying the 2D FFT to terrain heights. (a) Wavenumbers between 0 and $1 \mathrm{~km}^{-1}$ (wavelengths longer than 1 $\mathrm{km}$ ). (b) A detail for wavenumbers between 0 and $0.25 \mathrm{~km}^{-1}$ (wavelengths longer than $4 \mathrm{~km}$ ). 


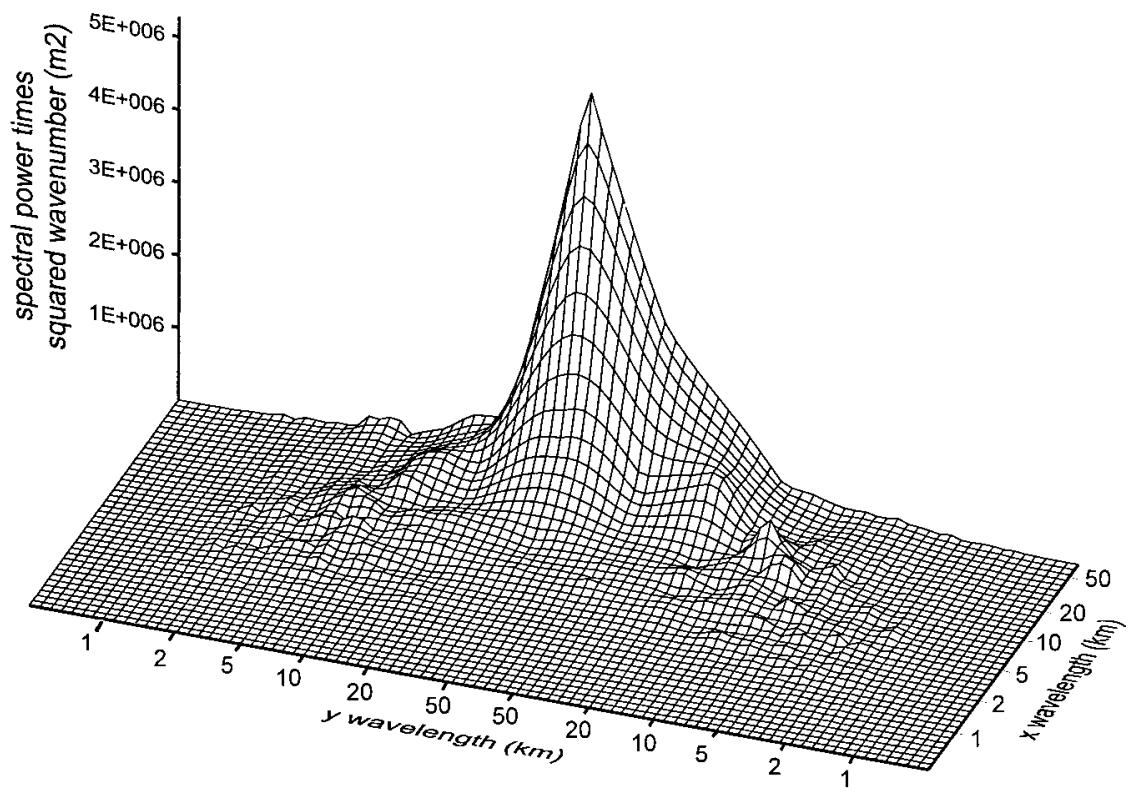

FIG. 3. Three-dimensional representation of the terrain spectrum. The product of the spectral power times the square of the wavenumber $\left(\mathrm{m}^{2}\right)$ is shown vs the wavelengths in a log scale. This representation enhances the analysis of long wavelengths, where most of the variance is contained.

numbers larger than $1 \mathrm{~km}^{-1}$ ( $\lambda$ shorter than $\left.1 \mathrm{~km}\right)$ is insignificant. The semicircular pattern of the isopleths means that there is no important directionality in this area. Nevertheless, a zoom of this picture, corresponding to wavelengths larger than $4 \mathrm{~km}$, is drawn in Fig. $2 \mathrm{~b}$ and shows some features that can be significant. In the upper half, a ridge of relative maximum values of spectral power appears (line A in the picture), which corresponds to the SW-NE direction and to $\lambda$ between 10 and $20 \mathrm{~km}$. This spectral ridge can be associated with the series of topographical valleys and ridges in the SENW direction, which were highlighted in a previous section (e.g., Mijares, Turia, Palancia valleys). In the lower half, two other axes ( $\mathrm{B}$ and $\mathrm{B}^{\prime}$ in the figure) are apparent. These axes of relatively high spectral power probably correspond to the coast line and the main mountain ridge that runs approximately parallel to the coast.

Another typical representation after Fourier analysis is the product of spectral power times wavenumber versus the logarithm of wavenumber (or wavelength). This relation is shown in Fig. 3. Note that in the present case, spectral power is multiplied by the square of wavenumber, since a 2D FFT has been applied. For negative wavenumbers the logarithm function should not work, but this difficulty has been avoided by considering that the negative sign of wavenumber has no physical meaning other than direction. Although equivalent to the previous representation, this approach is sometimes more adequate for identifying the wavelengths where most of the spectral power, that is, variability of the original terrain, is concentrated (Pielke and Kennedy 1980; Pielke 1984). The surface shown in Fig. 3 has been smoothed somewhat (through use of a running average) by the graphics software package, but there are some obvious features. First, most of the spectral power belongs to long waves $(\lambda>10 \mathrm{~km})$. Second, there is no significant variability for wavelengths shorter than $2 \mathrm{~km}$. Third, there is more variability associated with some specific directions, as explained above. Small relative maxima correspond to the A, B, and $\mathrm{B}^{\prime}$ axis in Fig. 2b and have been analyzed above. These axes are related to (a) valleys perpendicular to the coast, (b) the main mountain ridge, and (c) the coastline, respectively. Note that since the SGS database is used for this spectral analysis, spectral variance for wavelengths as short as $400 \mathrm{~m}$ could be captured in principle. When we say that there is no significant variability for wavelengths shorter than $2 \mathrm{~km}$, we mean that this variability has little relevance compared to the variability associated with larger wavelengths. This conclusion is restricted to our framework, that is, the domain size $(150 \mathrm{~km} \times 150 \mathrm{~km})$ and the minimum available resolution $(200 \mathrm{~m}$ in this case). Obviously, if we had studied, for example, a 1 $\mathrm{km}^{2}$ domain with a resolution of, say, $5 \mathrm{~m}$, we probably would have found significant variability at $200 \mathrm{~m}$ wavelengths.

The spectral rolloff, that is, logarithm of spectral amplitude versus logarithm of wavenumber, along several sections of the spectrum shown in Fig. 2 was also investigated. These graphs would represent the spectrum of all sections through the topography in a direction given by the orientation of the section in wavenumber space (Steyn and Ayotte 1985). Four sections have been considered in the analysis, corresponding to the southnorth, west-east, northwest-southeast, and southwest- 

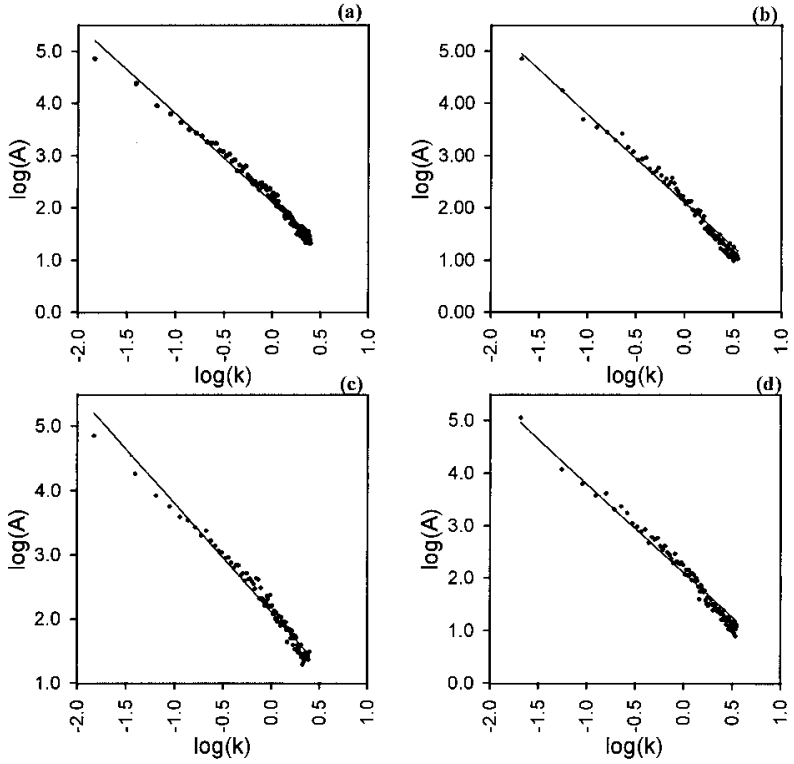

FIG. 4. Spectral rolloff, i.e., log of spectral amplitude vs log of wavenumber, for several directions obtained from sections of the terrain height spectrum: (a) west-east section, (b) southwest-northeast section, (c) southeast-northwest section, and (d) south-north section.

northeast directions (Fig. 4). In order to make them comparable to results presented by other authors, spectral amplitude (i.e., the square root of spectral power) was drawn on the ordinate axis. Then a linear regression between the logarithm of spectral amplitude and the logarithm of wavenumber was made, leading to a relation of the type $A=a \lambda^{b}$, where $A$ is the spectral power and $\lambda$ the wavelength. The two parameters $a$ and $b$ of the regression and the regression coefficients are given in Table 2 for each section. The values are not very diverse with respect to one another, as expected after the circular appearance of Fig. 2. The mean exponent $b(=1.77)$ is smaller than those presented by Steyn and Ayotte (1985) for topographies of British Columbia, Canada $(b=2.5)$, and Pennsylvania $(b=2.1)$. This fact means that the present domain is more complex than the terrain in those studies. That is, significant spectral energy exists for shorter wavelengths in the present terrain. Young and Pielke (1983) obtained a mean exponent of about 1.0 in their study of Colorado mountains, for the relation $S=a \lambda^{b}$. Note that although the interpretation of their parameter is the same as our exponents, values cannot be compared directly since their study used one-dimensional Fourier transforms, and established the relation for $S$ and not for $A$.

Based on the ideas presented by Young and Pielke (1983) but in order to make use of the full 2D terrain spectrum, the following method was derived to define the adequate grid size for a mesoscale model application over a specific topography. First, the energy of the height variance contained between wavenumbers $k_{1}$ and $k_{2}$ was defined:
TABLE 2. Parameters of the least squares best-fit relation of the form $A=a \lambda^{\mathrm{b}}$ for four sections through the terrain height spectrum; $r$ is the correlation coefficient.

\begin{tabular}{cccc}
\hline \hline Section & $a$ & $b$ & $r$ \\
\hline W-E & 2.103 & 1.695 & 0.97 \\
SW-NE & 2.070 & 1.838 & 0.98 \\
SE-NW & 2.076 & 1.874 & 0.98 \\
S-N & 2.121 & 1.700 & 0.98 \\
\hline \multirow{2}{*}{$E\left(k_{1}, k_{2}\right)=\int_{k_{1}}^{k_{2}} \int_{k_{1}}^{k_{2}} S\left(k_{x}, k_{y}\right) d k_{x} d k_{y}}$,
\end{tabular}

where $k_{x}$ is the wavenumber associated with the $x$ (westeast) axis, and $k_{y}$ is the wavenumber associated with the $y$ (south-north) axis. The total energy contained in the spectra is $E\left(k_{\min }, k_{\max }\right)$ where the minimum wavenumber (maximum wavelength) resolvable for a specific terrain is given by the extension $\left(L_{x}\right)$ of the domain $\left(k_{\min }=\right.$ $1 / L_{x}$ ), and the minimum wavelength (maximum wavenumber) is twice the grid resolution of the terrain data $\left[k_{\max }=1 /(2 \delta x)\right]$. Assuming that a numerical model cannot resolve any characteristic with a length scale less than $2 \Delta x$, and that an acceptable representation may require $4 \Delta x$ length scales (Uliasz et al. 1996), it is stated that the terrain energy considered by the mesoscale model is $E\left[\left(k_{\min }, 1 /(4 \Delta x)\right]\right.$. Therefore, given a domain of horizontal area $L_{x}$ times $L_{y}$, with a topography described with a minimum resolution $\delta x$, the ratio between the energy considered by a mesoscale model when using a grid size of $\Delta x$ and the total energy contained in the original topography is

$$
R=\frac{\int_{1 / L_{x}}^{1 /(4 \Delta x)} \int_{1 / L_{y}}^{1 /(4 \Delta x)} S\left(k_{x}, k_{y}\right) d k_{x} d k_{y}}{\int_{1 / L_{x}}^{1 /(2 \delta x)} \int_{1 / L_{y}}^{1 /(2 \delta x)} S\left(k_{x}, k_{y}\right) d k_{x} d k_{y}} .
$$

The value of this ratio for this study, based on the spectrum presented in previous figures and for several model grid sizes, is given in Table 3. If it is assumed,

TABLE 3. Ratio $R$ between model-resolved terrain variance and total terrain variance, and the grid resolutions for the scales of Castellón and the Iberian Peninsula that are necessary to achieve this ratio (considering that the model correctly represents wavelengths longer than $4 \Delta x$ ).

\begin{tabular}{ccc}
\hline \hline$R(\%)$ & $\Delta x($ Castellón $)$ & $\Delta x$ (Iberian Pen.) \\
\hline 99 & 0.5 & 2 \\
98 & 1 & 3.5 \\
97 & 1.5 & 5 \\
95 & 2 & 10 \\
92 & 4 & 18 \\
88 & 6 & 33 \\
80 & 10.5 & 60 \\
75 & 14 & 70 \\
70 & 16.5 & 85 \\
67 & 17.5 & 100 \\
\hline
\end{tabular}


for example, that including $95 \%$ of the terrain variance is sufficient to consider correctly the topographical forcing, the grid size required for this (Castellón) domain would be $2 \mathrm{~km}$. In Table 3 , results obtained by applying the methodology to the whole Iberian Peninsula (1800 $\mathrm{km} \times 1200 \mathrm{~km}$ domain size) with a minimum resolution of $30^{\prime \prime}$ also are presented. Analysis of this table allows one to establish that if the interaction between a greater scale (such as the case of the Iberian Peninsula) and the coastal atmospheric processes were to be included, it would be appropriate to use a $10-\mathrm{km}$ grid size for the former. This grid size would be recommended on the $\alpha$-mesoscale of the Iberian Peninsula when using nesting grids, in order to include an equivalent amount of terrain spectral energy in both domains (95\%).

\section{b. Mesoscale model}

To show the effect of considering different grid sizes in a mesoscale model application and, therefore, to illustrate better the interest of the results obtained by the spectral method, several simulations using the RAMS model with different horizontal spacing resolutions (Table 1) were compared. Model results were compared to measurements from ground-based monitoring stations, which are located in the domain (Fig. 1) as follows. There are two coastal sites: CS-Sur, located on the flood plain of Castellón $7 \mathrm{~km}$ inland, and Bartolo Mountain (BAR), placed $5 \mathrm{~km}$ inland on an isolated hill $(729 \mathrm{~m}$ altitude). There also are two inland sites: Cirat (CIR) station, located $41 \mathrm{~km}$ inland on top of a high $(470 \mathrm{~m})$ rocky abutment in the middle of the Mijares Valley, and the Valbona site (VNA), located $75 \mathrm{~km}$ inland on a small plateau at $965 \mathrm{~m}$ of altitude. Note that, except for Bartolo Mountain, these monitoring stations are in significant sites for describing the atmospheric flow.

Synoptic conditions for the selected day, 27 July 1989, showed the Azores anticyclone centered to the the southwest of Ireland, with an associated ridge aligned NW-SE between the Gulf of Biscay and the Spanish east coast (Fig. 5). A thermal low system, typical of the Iberian Peninsula summer, developed over the southern half of the peninsula. The thermal low intensified the pressure gradient between the northern coast and the center of the peninsula to a magnitude of about $8 \mathrm{hPa}$. The horizontal pressure gradient was weak over the studied domain, and thermally driven local flows (topography-induced flows coupled with sea breezes) developed. On the 500-hPa weather map, a divergence associated with the thermal low was observed at the south of the Iberian Peninsula. At this level, light geostrophic wind dominated in the area during the simulated period. Satellite photographs show clear skies over most of the Iberian Peninsula except northern Spain and Gibraltar. In the afternoon, cumulus clouds are observed in the center of Spain and over some coastal mountain ranges, indicating strong convection. Some cumulus clouds were observed around (a)

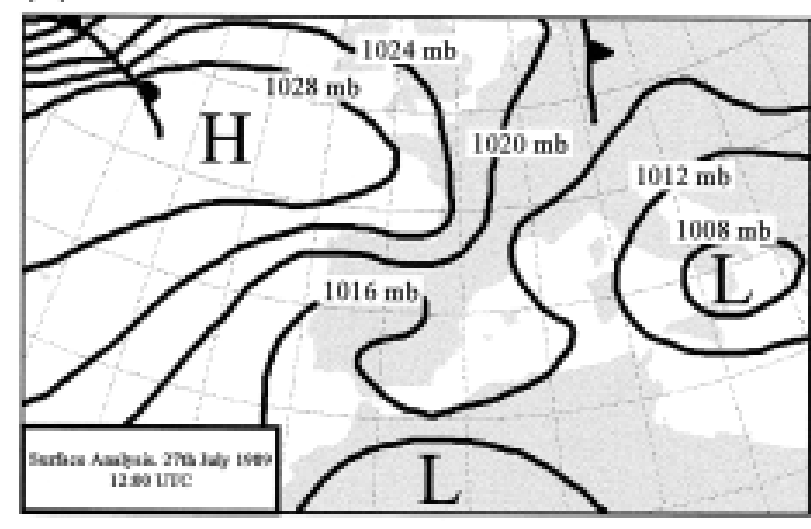

(b)

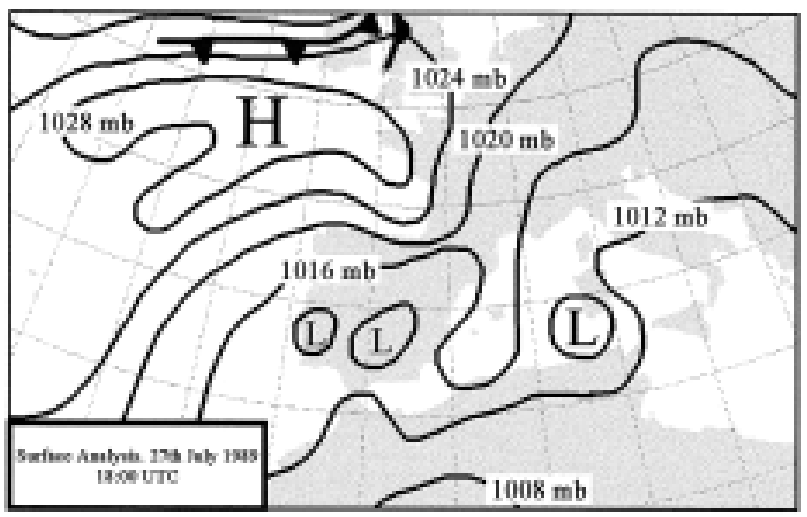

FIG. 5. Synoptic surface pressure maps from the Spanish Meteorological Institute at (a) 1200 and (b) 1800 UTC 27 Jul 1989. Isobars are plotted every $4 \mathrm{hPa}$.

noon, and were associated with the entrance of the sea breeze in the modeled domain (Millán et al. 1992). As mentioned before, however, microphysical cloud parameterization is not considered in these preliminary simulations.

\section{1) Horizontal PATtern OF ATMOSPHERIC FlOW}

Figure 6 presents RAMS-predicted surface layer wind streamline plots for four different model configurations. These representations emphasize regions of convergence and divergence. Terrain contours also are plotted; note how the model terrain of each run becomes more detailed because of the smaller grid increment. Simulations show that the main flow patterns are similar for the four runs, but some regions of flow divergence and convergence appear at different locations. At 0000 UTC, test 1 fails to simulate the coastal eddy that was produced by the other three runs. Two factors related to terrain resolution contribute to this result: first, the differences in the coastline shape, and second, the flow deflection at the Bartolo area foothills. Also, the vortices at the lee side of the Peñarroya and Javalambre Moun- 
(a)

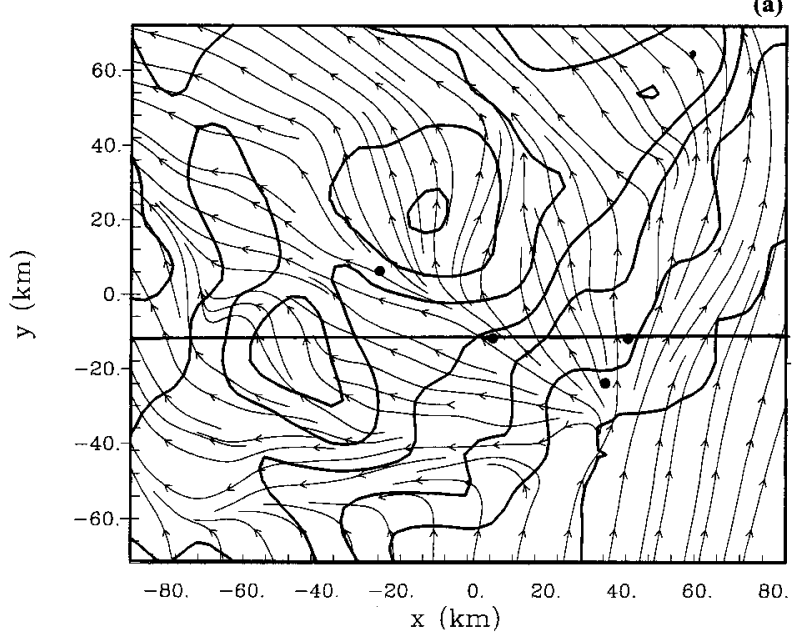

(c)

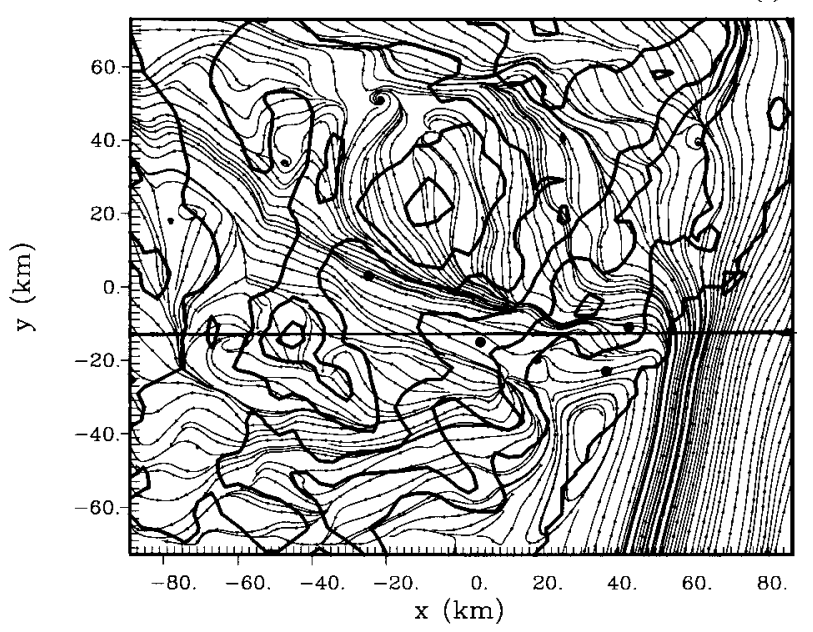

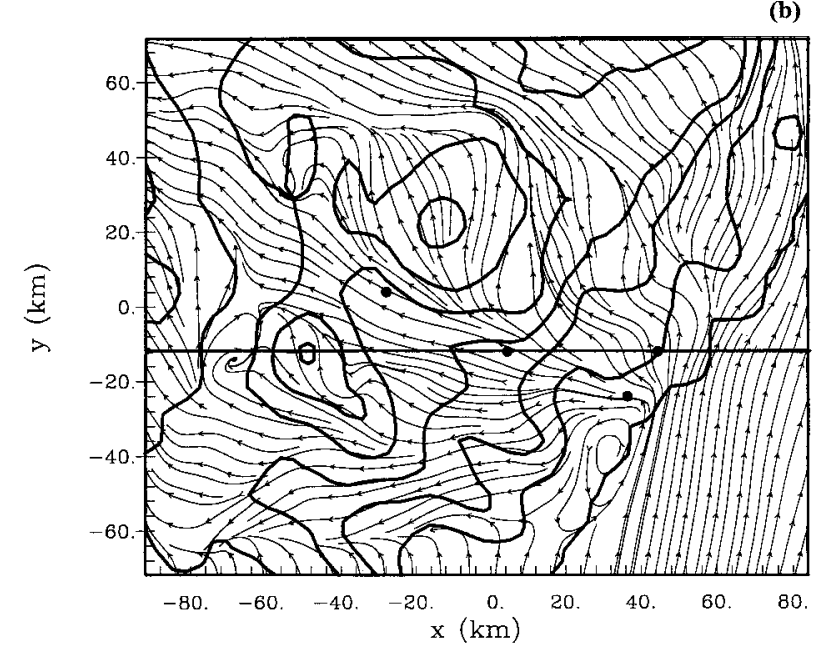

(b)

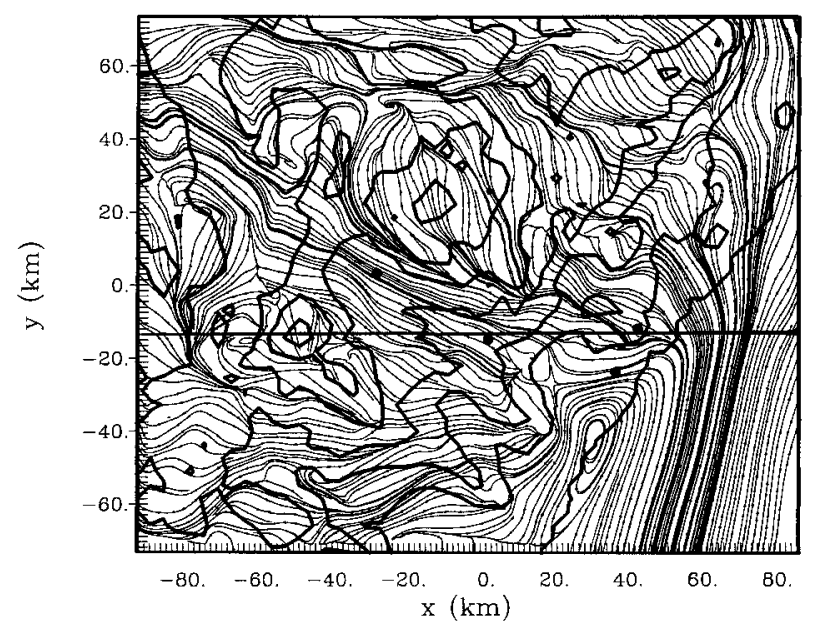

FIG. 6. Modeled surface layer wind streamlines at $57.3 \mathrm{~m}$ AGL for 0000 UTC 27 Jul 1989. (a) 6-km grid size; streamlines are plotted every two grid points. (b) 4-km grid size; streamlines are plotted every two grid points. (c) 2-km grid size; streamlines are plotted every four grid points. (d) $1.5-\mathrm{km}$ grid size; streamlines are plotted every four grid points. Terrain contours every $300 \mathrm{~m}$; monitoring stations are plotted as dots (see Fig. 1). Note the greater detail of terrain features as resolution increases. Straight lines through the figures indicate vertical cross sections to which the text refers.

tains are noticeable on test 2 , test 3 , and test 4 . Note that drainage flow is not simulated by the model at this height and time, but the model simulated nocturnal drainage flow after 0400 UTC (see the time series wind direction plots presented later in Fig. 15b). Observations showed nocturnal drainage flow around 2200 UTC of the previous day. This time lag may be explained by two reasons: either vertical resolution of the model was not sufficient, or initial conditions were not representative enough of actual conditions in the area and with time. Analysis of the experimental data revealed a shallow stable surface layer about $100 \mathrm{~m}$ deep, which almost corresponds to the first vertical model grid. Thus an additional experiment was performed with better vertical resolution, in which the first vertical grid layer top was set at $20 \mathrm{~m}$ AGL. However, drainage flow along the Mijares Valley was not modeled at 0000 UTC either (Fig. 7), leading us to conclude that the discrepancy between model and observations is caused mainly by inadequate initial conditions. Another simulation performed by the model, not presented in this paper, includes nesting capabilities and has solved this problem.

By 0600 UTC (Fig. 8), the time when minimum temperatures are reached, downslope flows on valley sidewalls were simulated by all model configurations, but test 3 and test 4 have more complex streamline patterns. Superposition of valley drainage flow and the slope wind system results in a wind vector convergence downward to the narrow valleys. Some features of the flow induced by topography appear only at the finer resolution grid runs (Fig. 9). These features include the counterclockwise turning of the wind associated with 
weak winds down the Mijares Valley near the VNA monitoring station; the flow deflection around the Bartolo Mountain area, which was not simulated by test 1 or test 2; and the divergence of the wind vectors on the lee side of Peñarroya mountain, around $50 \mathrm{~km}$ north and $10 \mathrm{~km}$ east, which is considerably more evident in test 3 and test 4 .

Isotach patterns at 0600 UTC (Fig. 10) show two aspects to be considered. First, the better the horizontal resolution, the higher the simulated downslope speed on the north side of the major mountain peaks (particularly north of Javalambre). Second, at the same time, there are pools of calm wind at the northwest of Gudar Mountains foothills, in Mijares Valley, and at the lee side of the Peñarroya. On the other hand, there is not much difference between test 3 and test 4 .

The horizontal wind patterns at 1200 UTC are depicted in Fig. 11. They are representative of the seabreeze period coupled with upslope and up-valley winds. Some features are similar in all the simulations: for instance, the location of a convergence line that extends from the Javalambre peak to the northern slope of Peñarroya. However, the wind vector convergence on the Mijares Valley is more evident in the finer grid spacing model simulations, with $\Delta x=2 \mathrm{~km}$ and $\Delta x=1.5$ km (Figs. 11c,d). Channeled winds along the Turia Valley and around the western foothills of Javalambre Mountain are well-simulated by all runs except for test 1. These winds cause divergence to the northwest of Javalambre except in test 1 , which predicts nearly calm conditions. Note also the strong winds at the Peñarroya peak for the higher resolution runs.

\section{2) Vertical structure of the convective LAYER}

The predicted vertical motions are quite sensitive to the horizontal grid size used. Vertical structure of the convective boundary layer as simulated by the four model configurations shows significant differences. Figure 12 shows the combined east-west component $(u, \mathrm{~m}$ $\left.\mathrm{s}^{-1}\right)$ and vertical wind component $\left(w, \mathrm{dm} \mathrm{s}^{-1}\right)$ plotted on the cross section depicted in Fig. 6. The section runs across the mountain peak of Javalambre and Bartolo Mountain. Solar heating of the mountain surface generates upslope and up-valley wind systems coupled with the sea breeze, which also generates convergence and updrafts near the peaks (Fig. 11). A tendency for thermal convection within the boundary layer appears in all simulations, although the test 1 and test 2 model runs show different and simpler patterns than the finer-scale runs. These cross sections of the wind show that finer-scale grid configurations simulated much higher and more intense vertical thermal updrafts. The maximum upward rate of ascent in the sea-breeze convergence zone was $146 \mathrm{~cm} \mathrm{~s}^{-1}$ using the $6-\mathrm{km}$ grid, while $450 \mathrm{~cm} \mathrm{~s}^{-1}$ was reached in the $1.5-\mathrm{km}$ grid configuration. These updraft cells could trigger cloud development and injection of

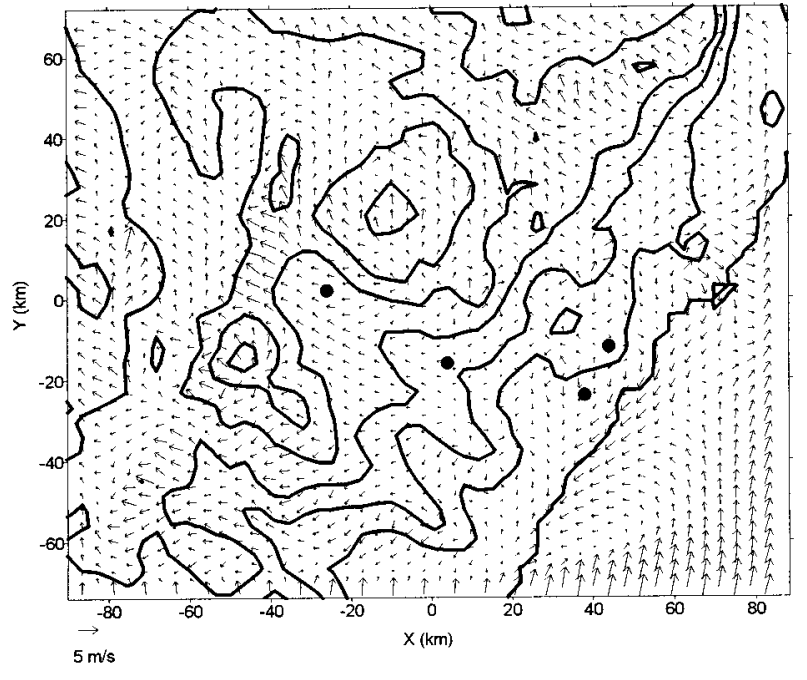

FIG. 7. Modeled (by test 5) surface layer wind field at $9.5 \mathrm{~m}$ AGL for 0000 UTC 27 Jul 1989. Terrain contours every $300 \mathrm{~m}$; monitoring stations are plotted as dots (see Fig. 1).

pollutants to upper layers, as has been observed (Millán et al. 1996). Although it is difficult to measure these vertical motions, hang-gliding practitioners in this area reported strong thermal (chimney) updrafts. In any case, some modeled vertical currents are strong but very localized. Generally, the inclusion of a finer grid increases the ability of meteorological models to produce larger vertical motion since small-scale horizontal temperature gradients and velocities can be resolved (Poulos and Pielke 1994).

Regarding mountain updrafts, Ulrickson and Mass (1990) reported converging flows that generate $50 \mathrm{~cm}$ $\mathrm{s}^{-1}$ updrafts over the ridges of the heated mountain slopes of the Los Angeles area. Their simulations used $5 \mathrm{~km}$ as the horizontal grid resolution. As they state, additional information about the significance of individual ridges and canyons would be required for an accurate simulation. This information, however, was omitted in that study because of the necessity of smoothing the terrain. Also, simulations performed by RAMS for the Kennedy Space Center (KSC) area in Florida, which would represent a flat coastal terrain mesoscale circulation, produced peak updrafts of $170 \mathrm{~cm} \mathrm{~s}^{-1}$ at midday (Lyons et al. 1993) when a grid spacing of 1 $\mathrm{km}$ was used. Doppler sodar field observations suggested vertical motions in the $1-2 \mathrm{~m} \mathrm{~s}^{-1}$ range during coastal field discontinuities in the KSC area. Poulos and Pielke (1994) also studied transport of pollutants in the Los Angeles Basin under stable stratified winter conditions. They pointed out the importance of terrain features by comparing flat to actual complex terrain simulations and by comparing different model resolutions. Model configuration consisted of three nested grids of 72,24 , and $8 \mathrm{~km}$. The largest vertical wind components modeled in that simulation were equal to $6 \mathrm{~cm} \mathrm{~s}^{-1}$ on the coarser grid $(24 \mathrm{~km})$ and $20 \mathrm{~cm} \mathrm{~s}^{-1}$ on the finer grid 


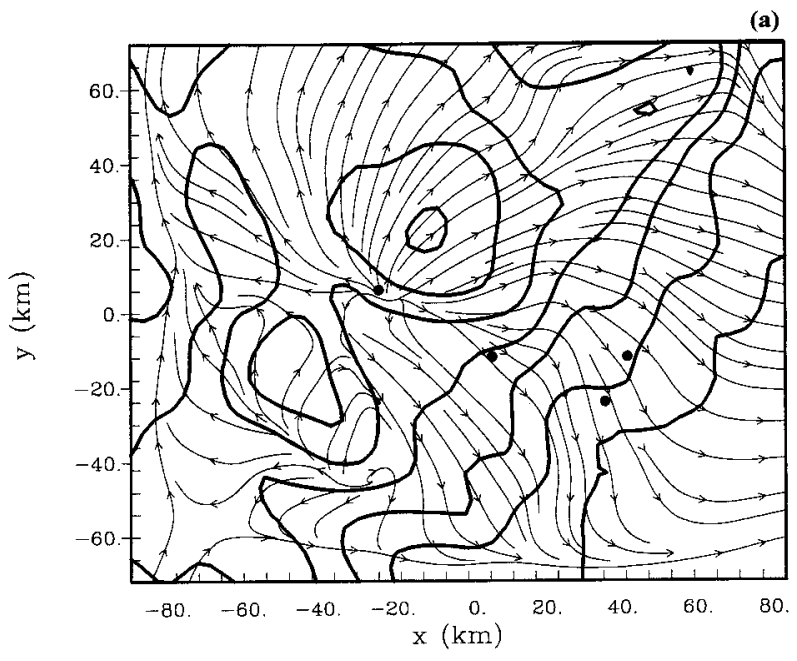

(a)

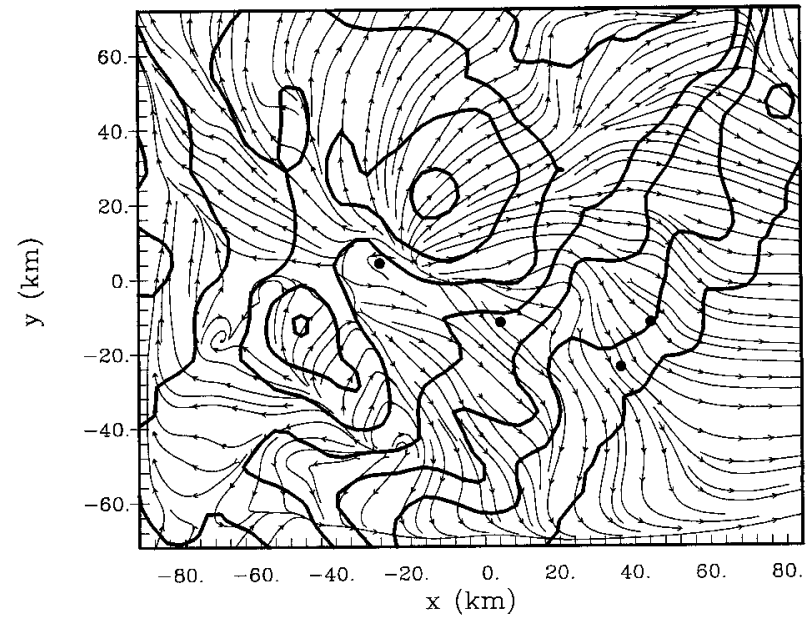

(c)
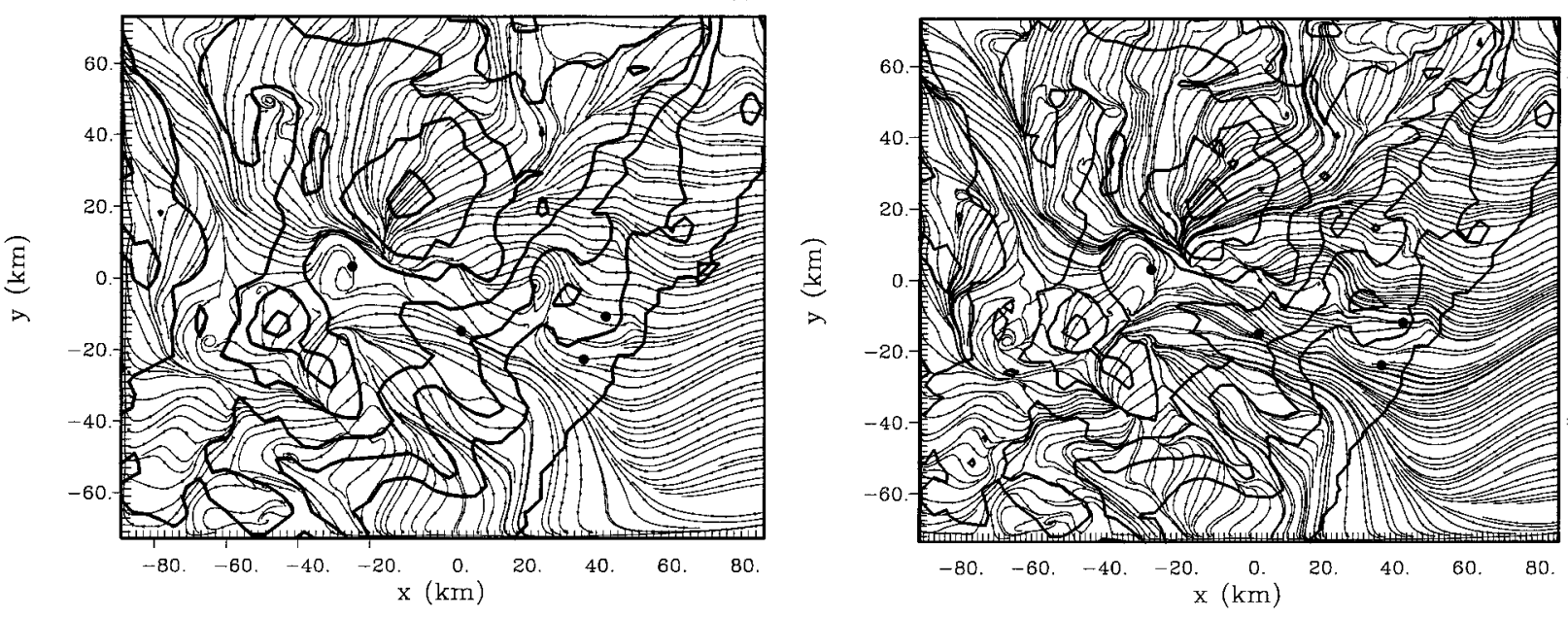

FIG. 8. Same as Fig. 6 but at 0600 UTC.

(8 km). Although Los Angeles topography can be compared in complexity with the terrain in our study area, the meteorological conditions and model configuration of the study cannot.

The influence of the horizontal grid spacing on the flow vertical structures is evident in Fig. 12. Although the flow is primarily thermally induced, underlying topography has a great impact on it. First, eastern mountain slopes can be heated more efficiently when they are steeper, and this heating can drive new thermal updrafts over relatively small terrain features. Second, mechanical effects associated with the coupling of the sea breeze with upslope flows enhance topographical injection. For example, test 1 simulates a main sea-breeze cell, with its convergence zone approximately on the main mountain ridge and a subsea-breeze-sized eddy at $x=30 \mathrm{~km}$. The return flow was simulated by test 1 at about $1300 \mathrm{~m}$ AGL. Meanwhile, test 3 and test 4 results show several small cells inside the general sea-breeze flow pattern: one at $x=30 \mathrm{~km}$ and another at $x=-10$ km (see Fig. 12d). These cells are associated with heated mountain slopes that hardly appeared in the coarser runs. In fact, test 4, which is the one containing greater than $95 \%$ of the terrain variance, shows a much stronger updraft than any of the other tests do at $x=-10 \mathrm{~km}$. In addition, a noticeable sinking area west of Javalambre mountain appears when using $\Delta x=1.5 \mathrm{~km}$ or $\Delta x=2$ $\mathrm{km}$. This downward motion was not modeled by tests that used $\Delta x=4 \mathrm{~km}$ or $\Delta x=6 \mathrm{~km}$.

Air potential temperature is presented in Fig. 13 on the same vertical cross sections. The pictures show that there is an increase in the vertical gradient of potential temperature within the cool marine boundary layer (MBL) as horizontal resolution increases, which is associated with the increase in downward motion seen in Figs. 12c,d. This fact might be due to a better description of the return subsidence flow over the MBL by the finerresolution tests. Note for example that the $306-\mathrm{K}$ isoline is much lower in test 3 or test $4[1100 \mathrm{~m}$ above mean sea level (MSL)] than it is in test 1 or test $2(1500 \mathrm{~m}$ 

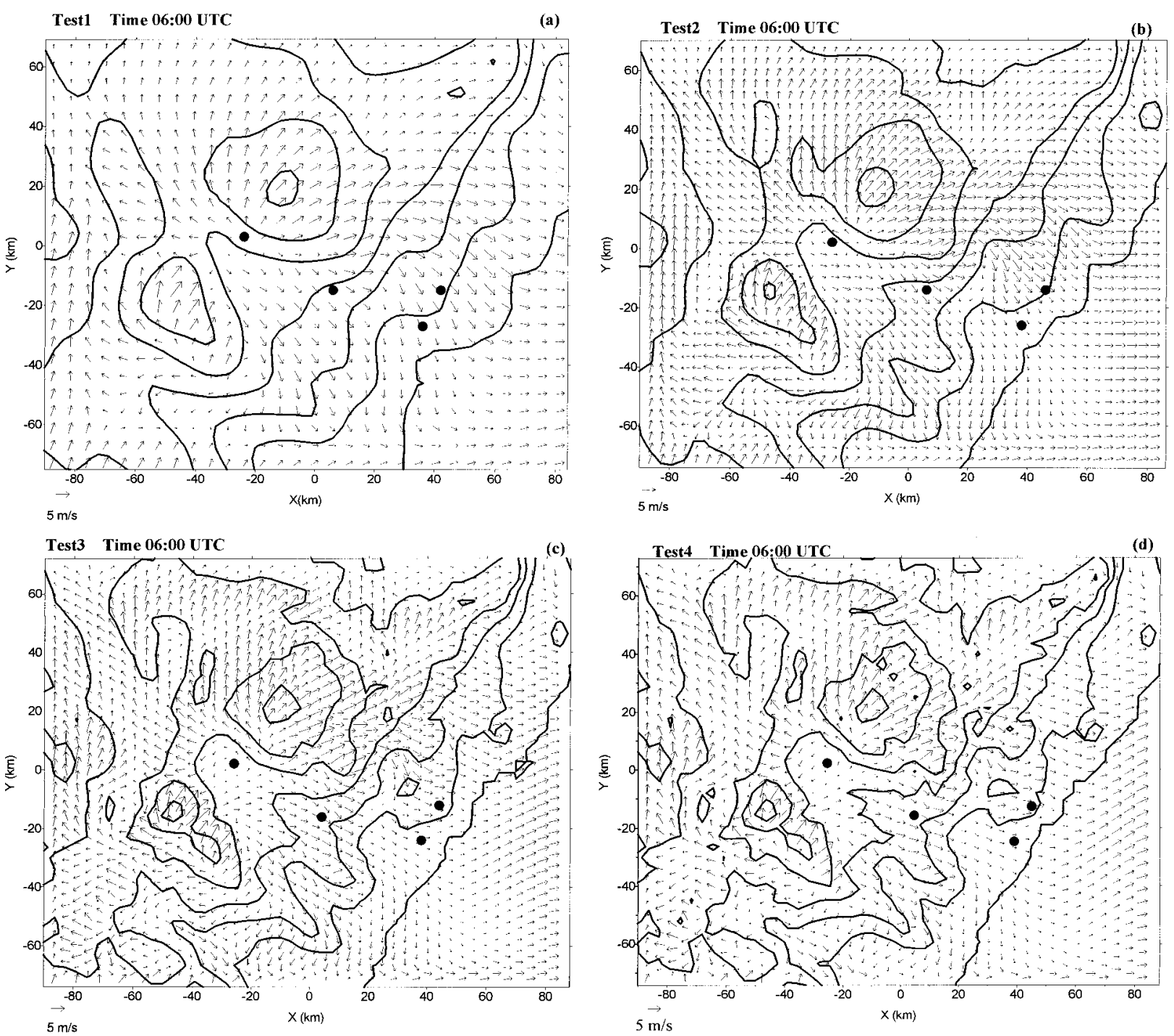

FIG. 9. Modeled surface layer wind pattern at $57.3 \mathrm{~m}$ AGL for 0600 UTC 27 Jul 1989. (a) 6-km grid size; wind vectors are plotted for all grid points. (b) 4-km grid size; wind vectors are plotted for all grid points. (c) 2-km grid size; wind vectors are plotted every four grid points. (d) $1.5-\mathrm{km}$ grid size; wind vectors are plotted every nine grid points. Terrain contours every $300 \mathrm{~m}$; monitoring stations are plotted as dots (see Fig. 1).

MSL). Over land, the isentropic surfaces show areas of baroclinicity that coincide with the position of the seabreeze frontal region, which is at similar locations in all the simulations. The greatest uplift of isentropes occurs where cells of upward motion were simulated for each test, respectively, and probably where the observed cumulus developed. Associated with the sinking air described above (west of Javalambre, $x=-70 \mathrm{~km}$ ), test 3 and test 4 show a layer of cooler air than is seen in the other tests.

Figure 14 shows turbulent kinetic energy (TKE), which is a measure of the intensity of turbulence and is proportional to the dispersion rate (Stull 1995). At 1200 UTC, vertical transport in thermals (created by superadiabatic conditions at the surface) brings TKE to higher altitudes, and the PBL structure is noticeable in all runs. However, the finer grids reproduce better a spatially wave-shaped boundary layer. The boundary layer oscillates in response to the processes that take place near the ground to achieve equilibrium, that is, to adjust turbulent fluxes into the generally unperturbed flow aloft. These processes are even more complex if interactions with onshore flow are considered. For all simulations, TKE decayed at elevations higher than $4000 \mathrm{~m}$ MSL (2000 m AGL) over the inland areas because of thermal static stability aloft. Almost no TKE is present over the sea, indicating a very shallow boundary layer. In coastal areas, turbulence is restricted to a depth of about $200-500 \mathrm{~m}$. Again, in high-resolution tests there is a particular phenomenon to the west of 
(a)
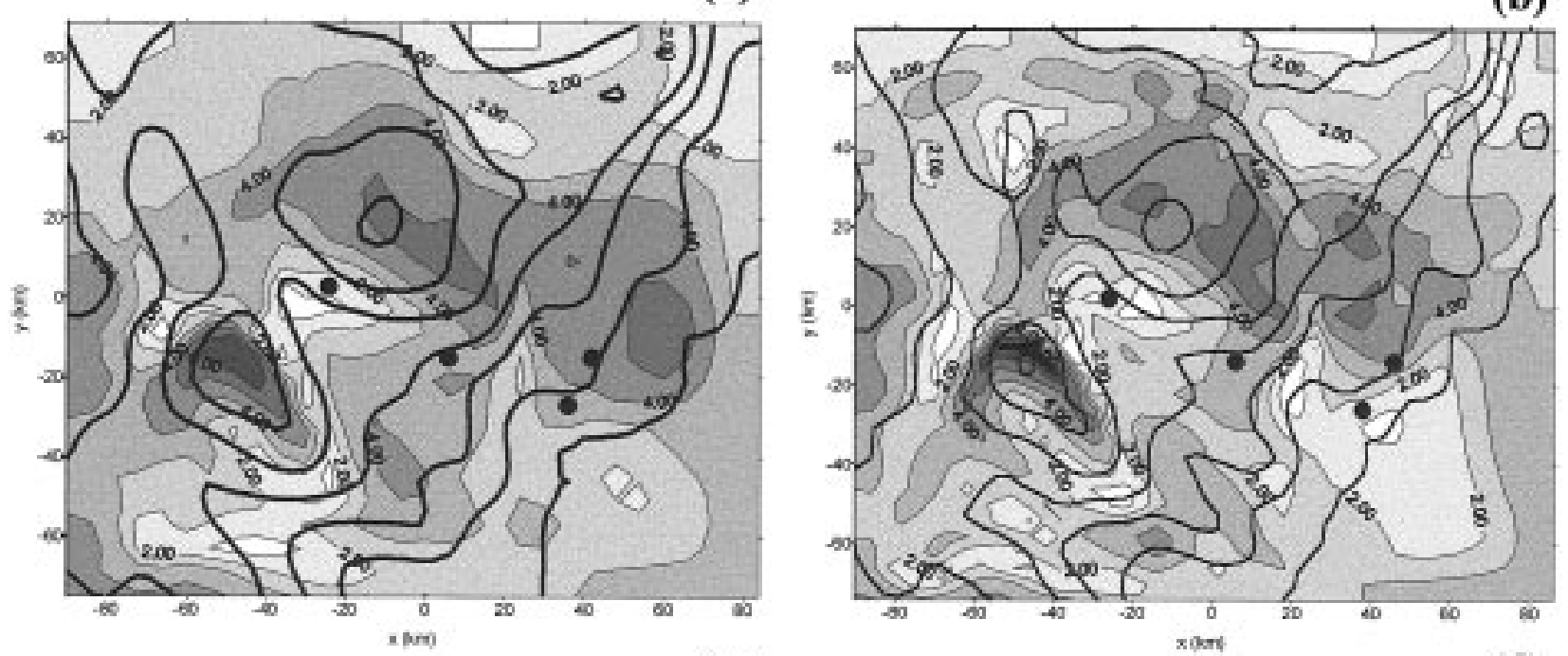

(c)
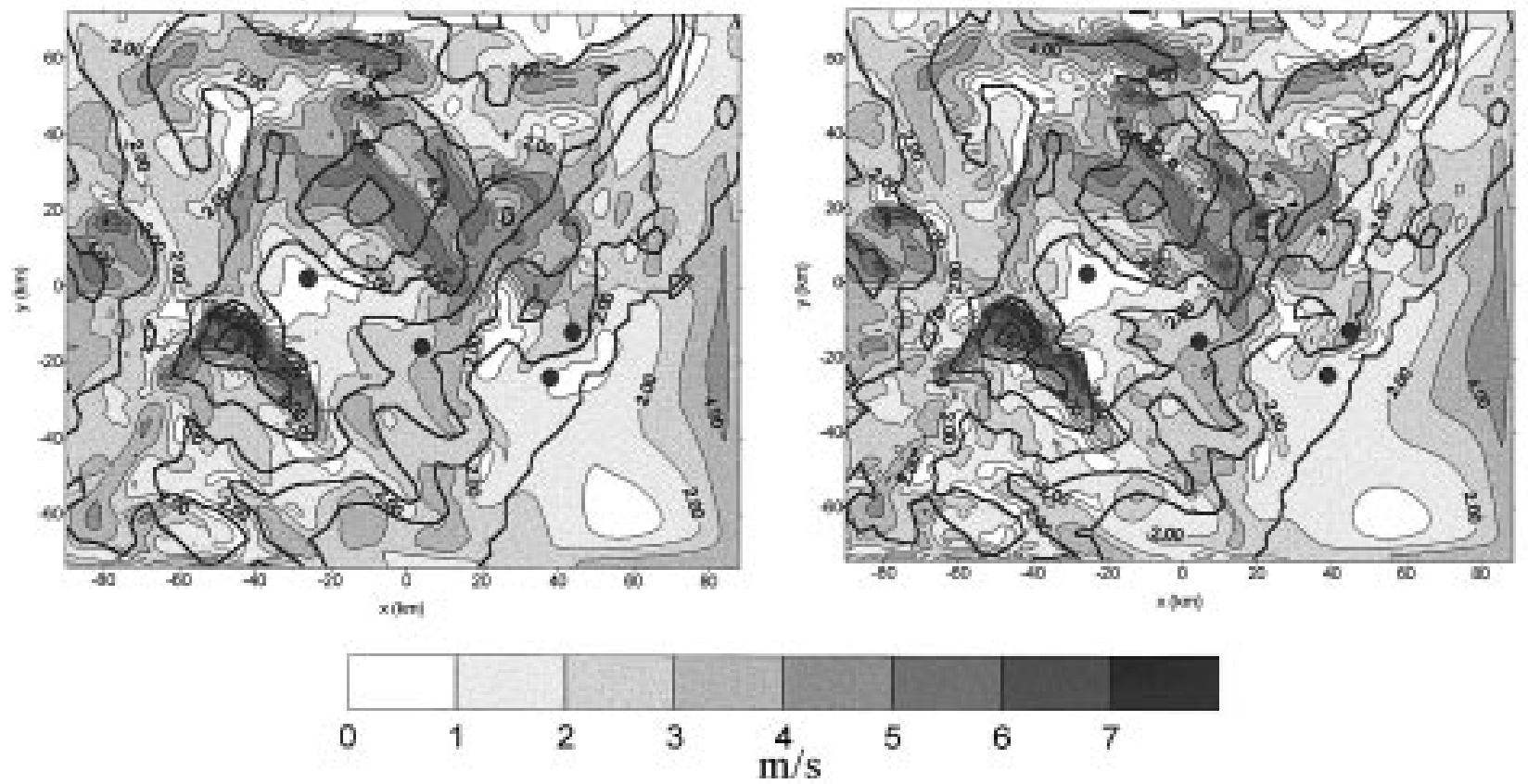

FIG. 10. Same as Fig. 9 but for isotachs every $1 \mathrm{~m} \mathrm{~s}^{-1}$.

Javalambre: because of the downward flow, the boundary layer becomes thinner in this area. Little turbulence was present at night or early in the morning and, therefore, results are not shown for these hours.

\section{3) Temperature AND Wind TIME SERIES}

Comparisons between modeled and observed data at four monitoring stations are shown in Fig. 15. For each station, values from the nearest grid point were used for comparisons, and modeled data were outputted every hour. The effect of horizontal grid size on modeled tem- peratures is remarkable while the sea breeze is blowing at coastal monitoring stations (CS-Sur and BAR). For example, there is a difference of about $4^{\circ} \mathrm{C}$ between maximum daily temperatures simulated by test 1 and test 4 at CS-Sur. On the contrary, modeled temperatures at inland sites do not show significant differences among the four tests (Fig. 15a). Modeled temperatures reach the morning minimum later than do observed temperatures. In addition, modeled minimum morning temperatures are a few degrees warmer than the observed values. This difference can be explained because the model's first vertical layer center is located at $57.3 \mathrm{~m}$ 

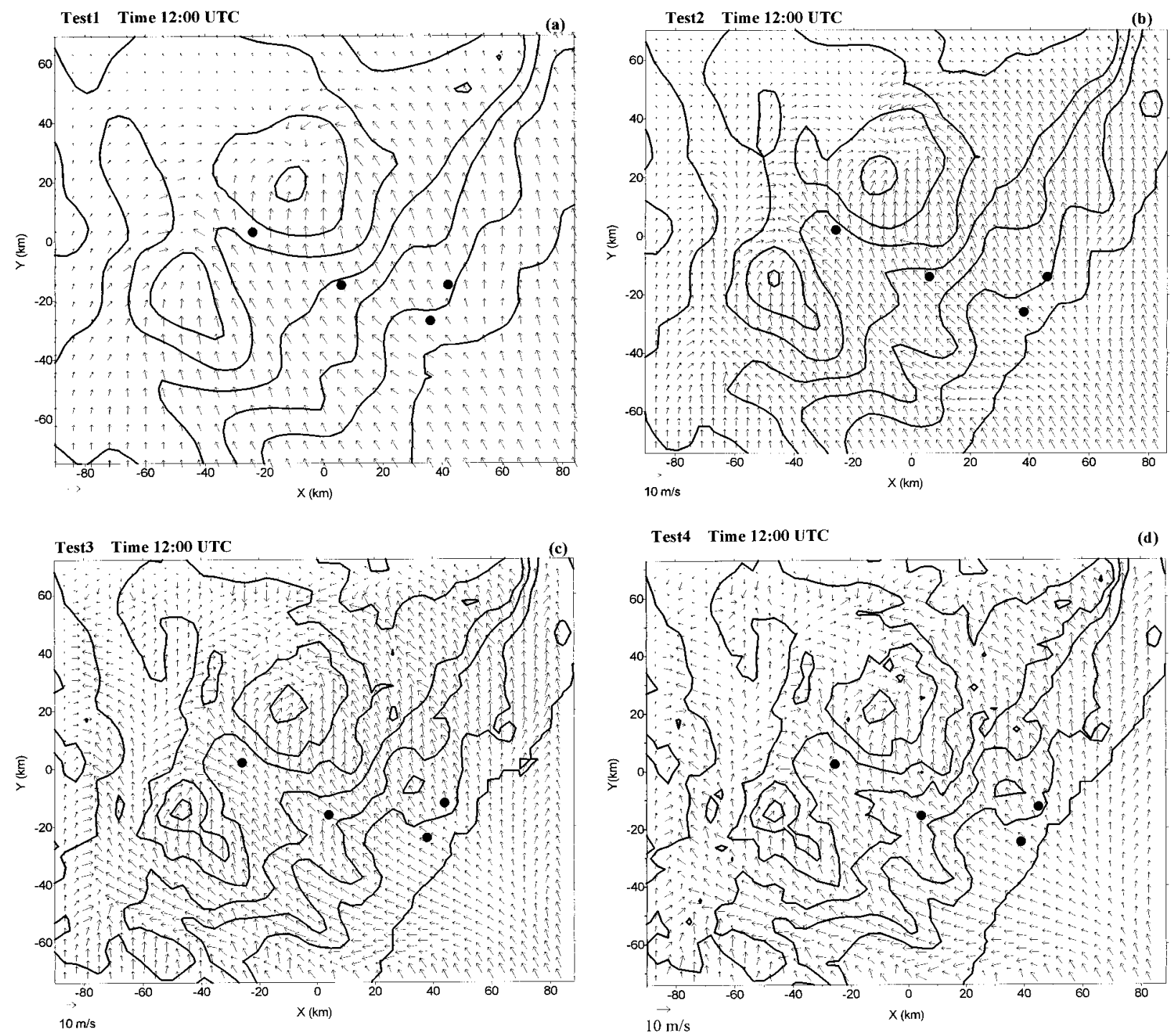

FIG. 11. Same as Fig. 9 but at 1200 UTC.

AGL in all tests but test 5, while meteorological towers measure at $10 \mathrm{~m}$; also, modeled results represent volume averages. Both the time when the minimum is reached and its value are simulated better by test 5 , that is, when a finer vertical resolution is considered. This is true at all stations but VNA, where, however, the morning maximum is estimated better by test 5 than by the other tests. In general, all tests underestimate temperature at the inland stations and overestimate it at the coastal stations. This discrepancy between modeled and observed data could be improved by a better definition of the soil characteristics, that is, initial soil moisture, soil texture, land use type, etc.

The BAR monitoring station is located on an isolated hill very close to the sea (Fig. 1b) and apparently was measuring very local effects that cannot be reproduced by even the finest grid. Note that even for the model configuration with the best vertical resolution (test 5), simulated temperatures at BAR follow a similar trend as at CS-SUR, which is representative of the coastal area. This similarity may mean that both the horizontal and the vertical spatial resolutions still are insufficient to reproduce the very particular features of this mountain. A similar daily temperature trend is observed at other isolated mountain stations close to the sea in the Mediterranean areas and under sea-breeze conditions (Tibidabo Mountain, 500-m height, $12 \mathrm{~km}$ from the coastline in Barcelona) (Calbó 1993).

Wind direction (Fig 15b) at CS-SUR is well reproduced during the whole day except late in the evening. However, wind direction late in the evening is not as relevant because nearly calm conditions were measured and also simulated. As mentioned before for the BAR monitoring station, all model runs fail to simulate the 


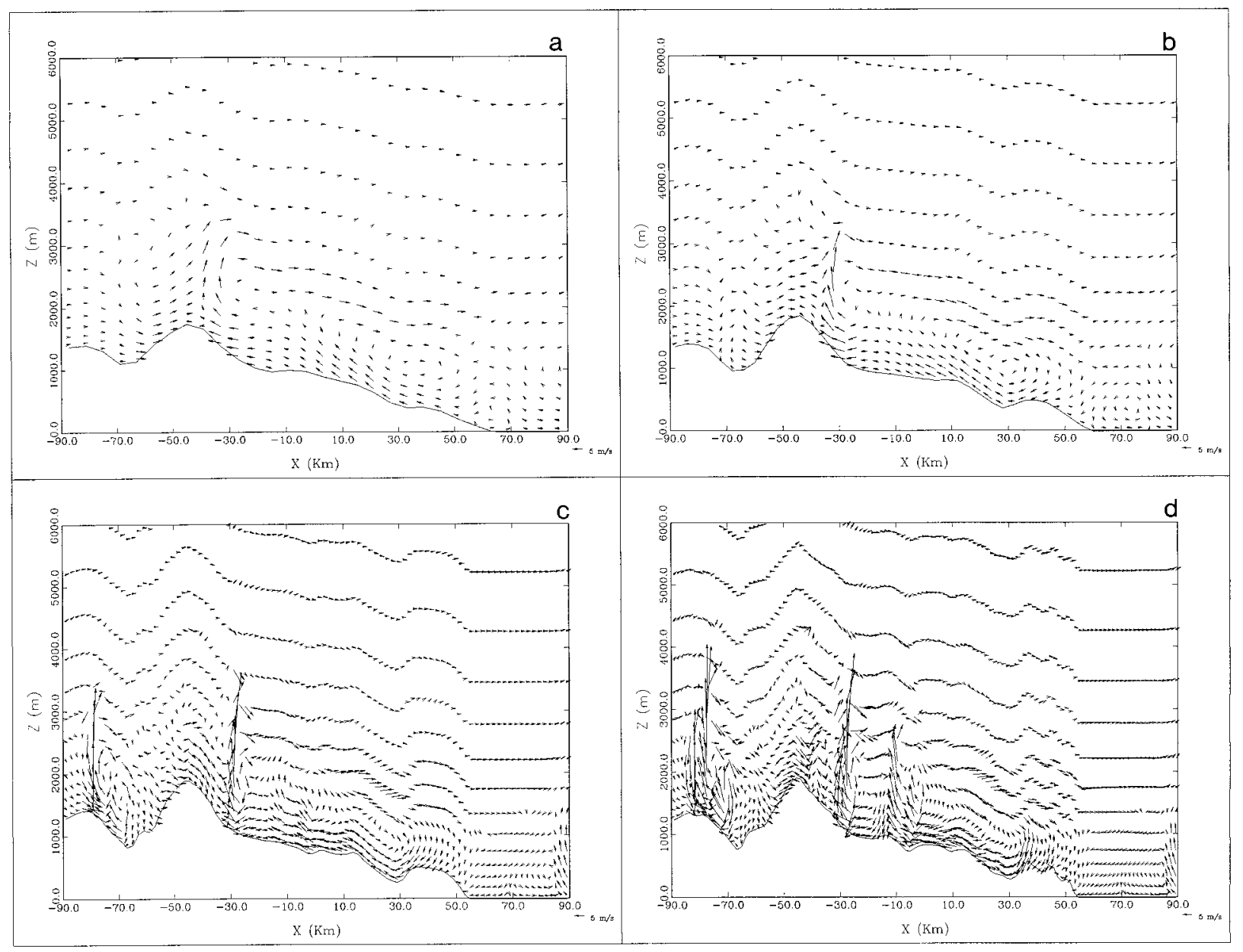

FIG. 12. Vertical cross sections of combined E-W wind component $\left(u, \mathrm{~m} \mathrm{~s}^{-1}\right)$ and vertical wind component ( $w$, dm s$\left.{ }^{-1}\right)$ at $1200 \mathrm{UTC} 27$ Jul 1989. The section along the W-E lines from Fig. 6 is shown for each test: (a) 6-km grid size, (b) 4-km grid size, (c) 2-km grid size, and (d) $1.5-\mathrm{km}$ grid size.

very local wind direction features that were measured. Model simulations give a typical sea-breeze daily cycle, while observations show opposite directions at this site. This discrepancy may be due to a very local phenomenon (such as a mountain wake) that again cannot be reproduced by the finer horizontal and vertical grids. It also could happen that the wind vane was recording spurious data. The wind direction of the nocturnal drainage conditions at the Cirat monitoring station is simulated better by the finest resolution configuration, but only when there is strong valley wind (between 0400 and 0900 UTC). The first hours of the nocturnal drainage flow at this site are not well simulated by either of the runs (Fig. 15b). This discrepancy between observed and simulated wind direction at Cirat might be due to wrong wind direction in the ECMWF initial conditions or to external processes that take place out of the modeling domain. Note that direction of nocturnal drainage flow is simulated better at this site (CIR) when using finer grids. Observed wind direction oscillations at VNA between 0800 and 1300 UTC are probably caused by topographically induced winds. Wind direction becomes steady with the arrival of the sea breeze around 1300 UTC. Neither model configuration was able to reproduce the first oscillations, although sea-breeze direction was estimated correctly by all tests. Observed data were sampled every 10 min while modeled data were outputted every hour.

Daily wind speed representative of sea-breeze conditions is overestimated in general (Fig. 15c). This result is because the center of the first vertical layer in the model $(57.3 \mathrm{~m})$ is well above the tower measurements at $10 \mathrm{~m}$. Therefore, a great improvement was achieved by test 5 , in which the center of the first vertical layer was set at $9.7 \mathrm{~m}$. This wind speed decrease is the most significant improvement obtained by this latter model configuration. The sharp rise of wind speed associated with the arrival of the sea breeze at VNA (1400 UTC) is well simulated by test 4 but not by the other tests.

\section{Conclusions}

The clear effect of grid resolution on a mesoscale meteorological model simulation in complex terrain has 

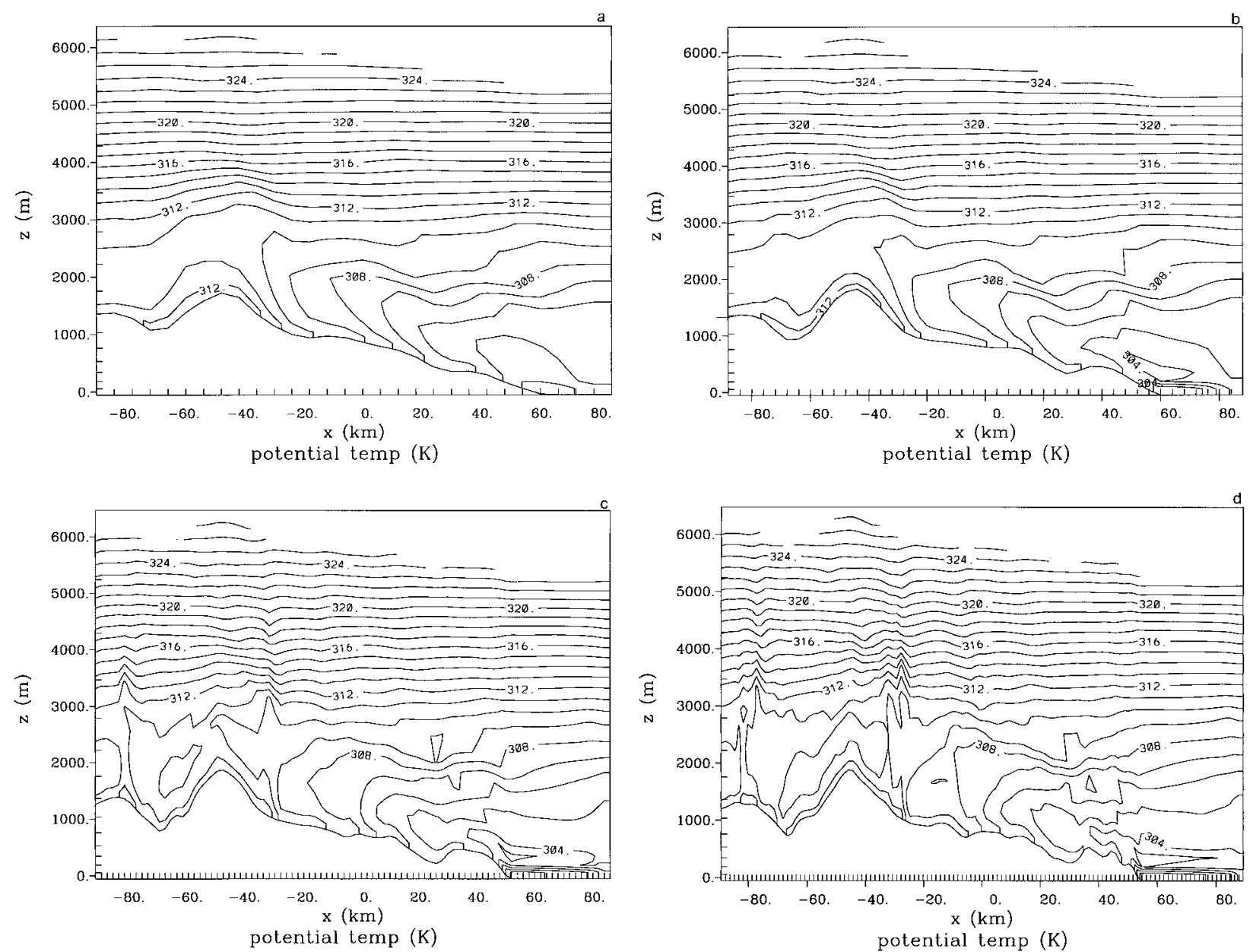

FIG. 13. Same as Fig. 12 but for simulated potential temperature (contour interval $=1 \mathrm{~K}$ ).

been illustrated in this work. In order to define objectively the grid size required to obtain an adequate representation of a given terrain, a methodology based on a two-dimensional Fourier transform of terrain heights has been presented. The two-dimensional spectrum has been analyzed and the equivalents of some terrain features have been shown in wavenumber space. A ratio has been defined between the terrain variance that is included in a simulation when using a specific grid size and the total variance of the terrain. For the domain studied here, a grid size of $2 \mathrm{~km}$ is needed to account for $95 \%$ of the variance, in contrast to a grid size of 10 $\mathrm{km}$, which would have included $80 \%$ of variance, or of $0.5 \mathrm{~km}$, which would have included $99 \%$. Note that computational time needed to carry out a simulation with a $0.5 \mathrm{~km}$ grid size would have been about 20 times greater than with $2 \mathrm{~km}$. We believe that the methodology presented in this paper can be used in any other study that pursues the adequate grid size for a mesoscale meteorological simulation in which topography is one of the major driving forces of the atmospheric dynamics.

The inclusion of $95 \%$ of terrain spectral power does not assure that all phenomena will be simulated correctly. It would mean that $95 \%$ of the terrain influence on atmospheric flows is captured. The missing 5\% may explain problems in particular locations such as Bartolo Mountain. In addition, note that we are studying exclusively the sensitivity to topography, but we do not consider other effects such as land use, soil moisture, or interaction with other atmospheric processes. It is hard to assure whether $95 \%$ is good enough for an application, although it can be good enough to capture the basic flow. However, the methodology allows one to know how much terrain variance is included or to decide how much one wants to include. A modeling experiment could use nesting capabilities to simulate a small area of interest with more detail. If nesting were used, and the modeler would like to be consistent, the same relative terrain variance should be included in the different grids. For the example given in the paper and if the relative variance included is $95 \%, 10 \mathrm{~km}$ should be used as the grid size for the (coarse grid) Iberian Peninsula domain and $2 \mathrm{~km}$ for the (fine grid) Castellón domain.

The effect of horizontal grid size on model results 

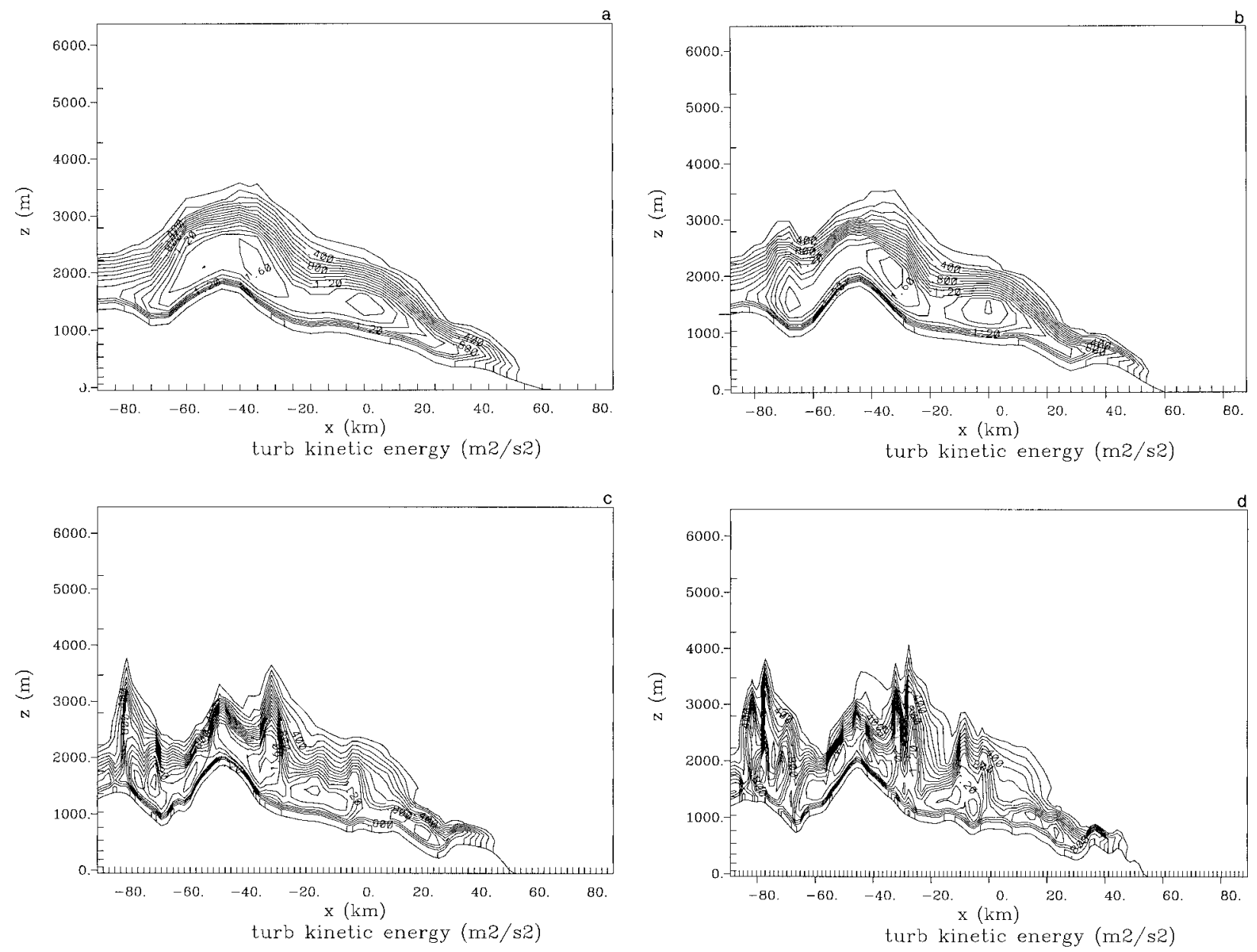

FIG. 14. Same as Fig. 12 but for simulated TKE (contour interval $=0.1 \mathrm{~m}^{2} \mathrm{~s}^{-2}$ ).

has been analyzed by means of four model configurations. Noticeable differences in the horizontal flow were found during nighttime and early in the morning. For example, finer grids simulate some pools of calm winds at the lee side of the mountains and higher wind speeds for downslope flows. In general, finer grids produce more complex patterns that show some eddies and vortices. It is very remarkable that horizontal grid size affects significantly the vertical structure of modeled atmospheric processes. In particular, stronger vertical wind components are predicted for finer grid resolutions. Also, several thermally induced circulation cells appear for those model configurations. The top of the PBL shows some oscillations associated with these cells that result in a more complex PBL structure. A deeper analysis of the involved phenomena could be carried out, but the goal of the present study was to show only the more significant differences created by different horizontal grid spacing.

It is well known that atmospheric processes drive pollutant dispersion. Therefore, if modeled pollutants are to be transported and diffused, they will experience quite different atmospheric conditions depending on simulated wind and turbulent patterns. For example, if pollutants were advected upward by the stronger vertical winds simulated by the finer grids, they would be injected up to a higher level and transported by the synoptic flow (Millán 1997). Results of the study by Ulrickson and Mass (1990) in the Los Angeles area point out the role of mountains in the ventilation of the basin prior to long-range transport of pollutants. Our model results suggest that important vertical advection takes place over the domain. This would result in significant transport of pollutants out of the PBL, subjected to longrange transport. These processes should be considered when continental simulations are to be carried out. In such simulations a very coarse horizontal grid usually is selected, leading to underestimation of this important vertical transport (Builtjes et al. 1997)

The selection of grid size is not, of course, the only prior analysis that should be made in any mesoscale model application. Regarding only the terrain, for example, the definition of nested grids and the description of soil characteristics from land use data are equally or even more important facts to consider. Besides, once the grid size has been selected, another question arises: what 

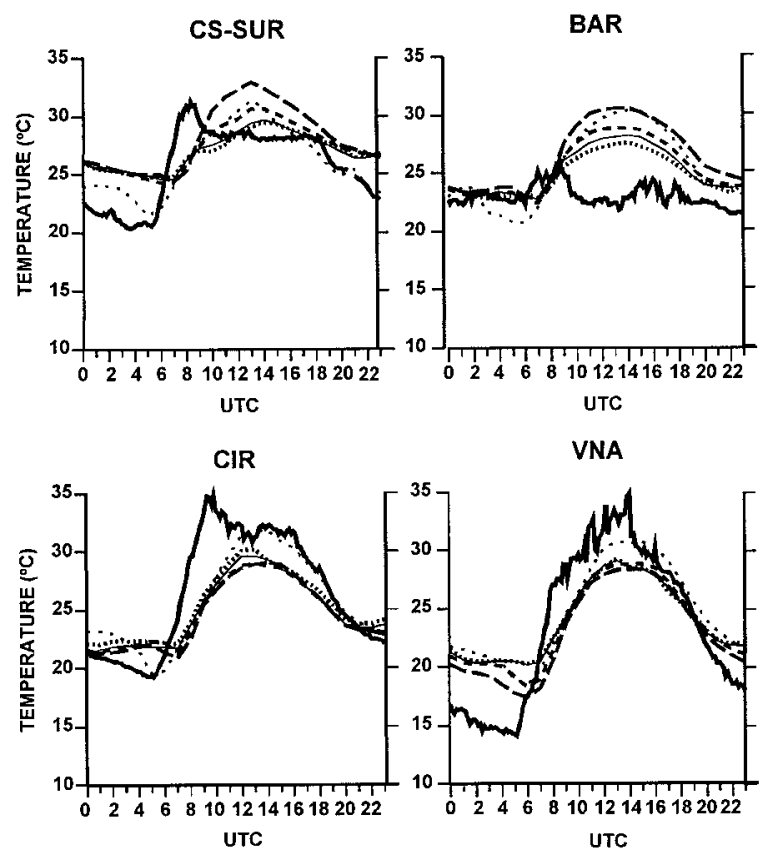

(a)
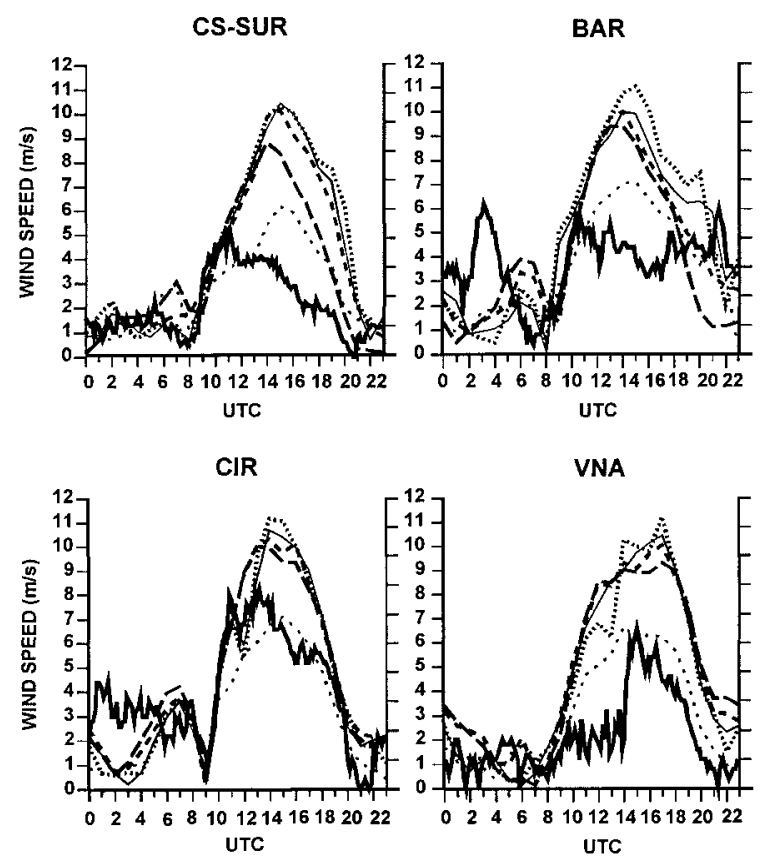

(c)

is the best description of a given terrain using the selected grid size? Some studies that include sampling, standard averaging, or silhouette averaging have been reported (e.g., McQueen et al. 1995). Some aspects of spectral analysis and the two-dimensional Fourier trans-
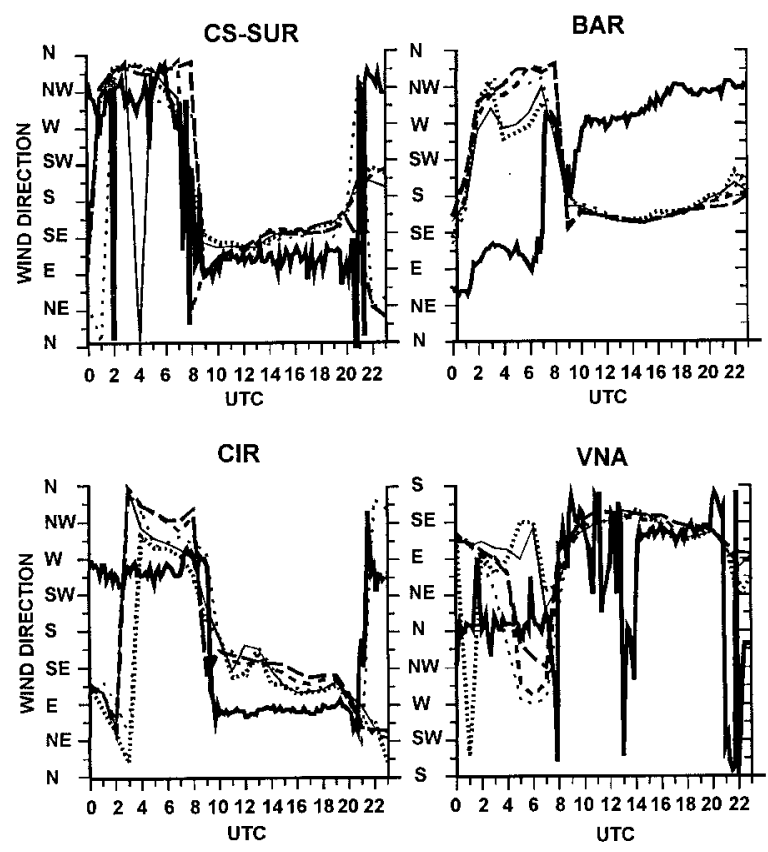

(b)

\begin{tabular}{|c|c|}
\hline OBSERVED & $\ldots$ TEST 3 \\
\hline - - TEST 1 & ........ TEST 4 \\
\hline$\ldots$ TEST 2 & .... TEST 5 \\
\hline
\end{tabular}

FIG. 15. Modeled and observed time series of (a) temperature, (b) wind direction, and (c) wind speed at the four ground-based monitoring locations for $27 \mathrm{Jul} \mathrm{1989.} \mathrm{Sites} \mathrm{are} \mathrm{described} \mathrm{in} \mathrm{section} 3$ b. forms in particular can help to obtain a good description of a terrain. This refinement, however, will be the subject of future work.

Acknowledgments. The authors would like to express 
thanks to the University Politécnica de Cataluña for the use of its facilities and especially to Prof. J. M Baldasano. This research was carried out using resources from CESCA and CEPBA, both coordinated by $\mathrm{C} 4$. The work presented here has been supported in part by the European Commission, under Project SECAP (EV5VCT91-0050-L), and by the CICYT of the Spanish Ministry for Science and Technology. The CEAM is financed by the Generalitat Valenciana and BANCAIXA. Thanks also to Maria Jose Salazar and Enrique Mantilla of CEAM for some of the graphics and Dr. Kallos and Dr. Kotroni of the University of Athens for their assistance in the use of RAMS.

\section{REFERENCES}

Builtjes, P. J. H., P. J. Esser, and M. G. M. Roemer, 1997: An analysis of regional differences in tropospheric ozone over Europe. Proceedings, 22d NATO/CCMS ITM on Air Pollution Modelling and its Application, Vol. 22, Plenum Press, 157-164.

Calbó, J., 1993: Contribució al desenvolupament d'un model meteorológic de mesoscala (Development of a mesoscale meteorological prognostic model). Ph.D. thesis, Universitat Politècnica de Catalunya, 337 pp. [Available from Department de Física, Universitat de Girona, Campus Motilivi, 17071 Girona, Spain.]

Ford, E. D., 1976: The canopy of a scots pine forest: Description of a surface of complex roughness. Agric. Meteor., 17, 9-32.

Garand, L., 1988: Automated recognition of oceanic cloud patterns. Part I: Methodology and application to cloud climatology. $J$. Climate, 1, 20-39.

Hernández, J. F., L. Cremades, and J. M. Baldasano, 1995: Dispersion modelling of a tall stack plume in the Spanish Mediterranean coast by a particle model. Atmos. Environ., 29, 1331-1341.

Lyons, W. A., R. A. Pielke, W. R. Cotton, M. Uliasz, C. J. Tremback, and R. L. Walko, 1993: The applications of new technologies to modeling mesoscale dispersion in coastal zones and complex terrain. Int. Symp. in Air Pollution, P. Zanetti et al., Eds., Computational Mechanics Publications and Elsevier Applied Science, $35-85$.

Martin, M., J. Plaza, M. D. Andrés, J. C. Bezares, and M. M. Millán, 1991: Comparative study of seasonal air pollutant behavior in a Mediterranean coastal site: Castellón (Spain). Atmos. Environ., 25A, 1523-1535.

McQueen, J. T., R. D. Draxler, and G. D. Rolph, 1995: Influence of grid size and terrain resolution on wind field predictions from an operational mesoscale model. J. Appl. Meteor., 34, 21662181.

Mellor, G. L., and T. Yamada, 1982: Development of a turbulence closure model for geophysical fluid problems. Rev. Geophys. Space Phys., 20, 851-875.

Millán, M. M., B. Artiñano, L. A. Alonso, M. Castro, R. FernandezPatier, and J. Goberna, 1992: Meso-meteorological cycles of air pollution in the Iberian Peninsula (MECAPIP). Air Pollution Research Rep. 44, EUR 14343, Commission of the European Communities, 291 pp. [Available from CEC-DG XII/E-1, Rue de la Loi, 200 Brussels, Belgium.]

_ R. Salvador, E. Mantilla, and B. Artiñano, 1996: Meteorology and photochemical air pollution in southern Europe: Experimental results from EC research projects. Atmos. Environ., 30, 1909-1924.

- $\longrightarrow,-$, and G. Kallos, 1997: Photooxidant dynamics in the Mediterranean basin in summer: Results from European research projects. J. Geophys. Res., 102 (D7), 8811-8823.

_ M. J. Estrela, and C. Badenas, 1998: Meteorological processes relevant to forest fire dynamics on the Spanish Mediterranean coast. J. Appl. Meteor., 37, 83-100.

— - E. Mantilla, R. Salvador, M. J. Sanz, D. Carratalá, L. Alonso, G. Gangoiti, and M. Navazo, 1999: Ozone cycles in the Western Mediterranean Basin: Interpretation of monitoring data in complex coastal terrain. J. Appl. Meteor., in press.

Pielke, R. A., 1984: Mesoscale Meteorological Modeling. Academic Press, $611 \mathrm{pp}$.

— ENV SCI-MESO-1980-1, University of Virginia, 21 pp. [Available from R. Pielke, Dept. Atmos. Sci., Colorado State University, Fort Collins, CO 80523.]

— elling system-RAMS. Meteor. Atmos. Phys., 49, 69-91.

Porch, W. M., 1982: Implication of spatial averaging in complexterrain wind studies. J. Appl. Meteor., 21, 1258-1265.

Poulos, G. S., and R. A. Pielke, 1994: A numerical analysis of Los Angeles Basin pollution transport to the Grand Canyon under stably stratified, southwest flow conditions. Atmos. Environ., 28, 3329-3357.

Press, W. H., B. Flannery, S. A. Teukolsky, and W. T. Vetterling, 1988: Numerical Recipes. The Art of Scientific Computing. Cambridge University Press, $702 \mathrm{pp}$.

Rayner, J. N., 1972: The application of harmonic and spectral analysis to the study of terrain. Spatial Analysis in Geomorphology, R. J. Chorley, Ed., Methuen and Co., 283-302.

Salvador, R., E. Mantilla, M. J. Salazar, and M. Millán, 1994: Plume dispersion modelling during a sea-breeze event. Air Pollution II, J. M. Baldasano et al., Eds., Vol. 2, Computational Mechanics Publications, 69-80.

Seufert, G., Ed., 1997: BEMA: A European Commission project on biogenic emissions in the Mediterranean area. Atmos. Environ., 31, SI 1-SI 255.

Steyn, D. G., and K. W. Ayotte, 1985: Application of two-dimensional terrain height spectra to mesoscale modeling. J. Atmos. Sci., 42, 2884-2887.

Stull, R. B., 1995: Meteorology Today for Scientists and Engineers. West Publishing Company, 385 pp.

Troen, I., and E. L. Petersen, 1989: European Wind Atlas. Riso National Laboratory, Roskilde, $656 \mathrm{pp}$.

Uliasz, M., R. A. Stocker, and R. A. Pielke, 1996: Regional modeling of air pollution transport in the southwestern United States. Environmental Modeling, P. Zannetti, Ed., Vol. 3, Computational Mechanics Publications, 145-182.

Ulrickson, B. L., and C. F. Mass, 1990: Numerical investigation of mesoscale circulations over the Los Angeles Basin. Part II: Synoptic influences and pollutant transport. Mon. Wea. Rev., 118, $2162-2184$

Walmsley, J. L., J. R. Salmon, and P. A. Taylor, 1982: On the application of a model of boundary-layer flow over low hills to real terrain. Bound-Layer Meteor., 23, 17-46.

Young, G. S., and R. A. Pielke, 1983: Application of terrain height variance spectra to mesoscale modeling. J. Atmos. Sci., 40, 25552560 . 